\title{
Analysis of epidermis- and mesophyll-specific transcript accumulation in powdery mildew-inoculated wheat leaves
}

\author{
Rémy Bruggmann ${ }^{1}$, Olaf Abderhalden ${ }^{1}$, Philippe Reymond ${ }^{2}$ and Robert Dudler ${ }^{1, *}$ \\ ${ }^{1}$ Institute of Plant Biology, University of Zurich, Zollikerstrasse 107, CH-8000, Zürich, Switzerland (*author \\ for correspondence; e-mail rdudler@botinst.unizh.ch); ${ }^{2}$ Department of Plant Molecular Biology, University of \\ Lausanne, Biology Building, CH-1015, Lausanne, Switzerland
}

Received 12 January 2005; accepted in revised form 3 March 2005

Key words: acquired resistance, cDNA-AFLP, microarray, powdery mildew, tissue-specific gene expression, wheat

\begin{abstract}
Powdery mildew is an important disease of wheat caused by the obligate biotrophic fungus Blumeria graminis f. sp. tritici. This pathogen invades exclusively epidermal cells after penetrating directly through the cell wall. Because powdery mildew colonizes exclusively epidermal cells, it is of importance not only to identify genes which are activated, but also to monitor tissue specificity of gene activation. Acquired resistance of wheat to powdery mildew can be induced by a previous inoculation with the non-host pathogen $B$. graminis $\mathrm{f}$. sp. hordei, the causal agent of barley powdery mildew. The establishment of the resistant state is accompanied by the activation of genes. Here we report the tissue-specific cDNA-AFLP analysis and cloning of transcripts accumulating 6 and $24 \mathrm{~h}$ after the resistance-inducing inoculation with B. graminis f. sp. hordei. A total of 25000 fragments estimated to represent about 17000 transcripts were displayed. Out of these, 141 transcripts, were found to accumulate after Bgh inoculation using microarray hybridization analysis. Forty-four accumulated predominantly in the epidermis whereas 76 transcripts accumulated mostly in mesophyll tissue.
\end{abstract}

\section{Introduction}

Powdery mildew is an important disease of wheat (Triticum aestivum $\mathrm{L}$.). It is caused by the obligate biotrophic fungus Blumeria graminis f. sp. tritici $(B g t)$ which colonizes exclusively epidermal cells of the host by penetrating directly through the cell wall and forming haustoria inside by invagination of the plasmalemma. Resistance to powdery mildew disease can be conferred by race-specific resistance genes, and the first one in wheat has recently been cloned (Yahiaoui et al., 2004). Although such genes have been widely used in breeding programs, they are usually not durable because new virulent pathogen races emerge quickly. A more durable form of resistance observed in many plants is acquired resistance, which is a form of physiological resistance effective against a broad spectrum of pathogens. It is induced by a trigger event such as an attack by an incompatible pathogen. In many plant species, a local triggering event leads to the induction of resistance of the whole plant (systemic acquired resistance, SAR; Ryals et al., 1996; Sticher et al., 1997; Durrant and Dong, 2004). In wheat, local acquired resistance against powdery mildew can be triggered by inoculation with spores of $B$. graminis f. sp. hordei $(B g h)$, the powdery mildew of barley for which wheat is not a host.

Acquired resistance is accompanied by the activation of genes, including the well-known pathogenesis-related (PR) genes (Hunt and Ryals, 1996; Maleck et al., 2000). It is thought and has been experimentally demonstrated in a number of host-pathogen systems that the products of 
activated genes can be causally related to the physiologically resistant state (e.g. Broglie et al., 1991; Alexander et al., 1993; Liu et al., 1994; Jach et al., 1995; Grison et al., 1996). In wheat, some of these defense-related genes were demonstrated to reduce the penetration efficiency of $B g t$ when transiently overexpressed in wheat epidermal cells (Schweizer et al., 1999a,b), and one was recently constitutively and specifically expressed in the epidermis of transgenic wheat plants, resulting in elevated resistance against powdery mildew (Altpeter et al., in press). Thus, the knowledge of genes activated, particularly in the epidermis, upon induction of acquired resistance is important and may lead to a better understanding of the molecular resistance mechanism and the biotechnological development of increased and durable resistance against powdery mildew in wheat.

The aim of the study presented here was to identify host genes induced in the epidermis of $B g h$ treated wheat leaves because the corresponding gene products may be directly responsible for resistance induction. Therefore, an RNA fingerprinting method, cDNA-AFLP (amplified fragment length polymorphism; Vos et al., 1995; Bachem et al., 1996), was applied using epidermis preparation as the starting material for the identification of transcripts accumulating in the epidermis upon $B g h$ inoculation. cDNA-AFLP displayed a total of 363 differentially expressed cDNA fragments 6-9 and 23-26 h post-inoculation (hpi). To analyse the expression of the corresponding genes in more detail, the fragments were subcloned and arrayed on glass slides. Microarrays were hybridised to cDNA probes derived from epidermal and mesophyll preparations as well as from whole leaves of $B g h$-inoculated and un-inoculated control plants. The experiments identified 44 genes predominantly activated in the epidermis, many of which were novel or not known to be activated by pathogen inoculation, as well as 80 genes whose transcripts accumulated predominantly in mesophyll tissue.

\section{Results}

cDNA-AFLP analysis and cloning of transcripts from Bgh-inoculated epidermis preparations

Seven-day-old wheat seedlings (Triticum aestivum cv. Fidel) were inoculated with Blumeria graminis $\mathrm{f}$. sp. hordei $(B g h)$ at a density of approximately $200 \mathrm{conidia} / \mathrm{mm}^{2}$. The abaxial epidermis of primary leaves of $B g h$-inoculated and uninoculated control plants was harvested 6-9 and $23-26 \mathrm{~h}$ post-inoculation (hpi), respectively. Since the isolation of epidermal tissue was time-consuming, material was collected during $3 \mathrm{~h}$. For simplicity, the time range 6-9 and 23-26 hpi are referred to as 6 and $24 \mathrm{hpi}$, respectively. The first collection period coincides approximately with appressorium formation, the second one with haustorium establishment. RNA was extracted from the collected plant material and used for cDNA-AFLP analysis according to (Vos et al., 1995; Bachem et al., 1996). The cDNA fragments were amplified using all possible 256 selective primer combinations. The size of the AFLP fragments ranged from 50 to $700 \mathrm{bp}$; for each primer combination, $80-120$ bands were observed. The majority of the bands showed no change in the intensity between different lanes. In total, 25000 fragments were displayed, representing $\sim 17000$ mRNA as estimated on the basis of the analysis of 80 random wheat $\mathrm{cDNA}$ sequences from nucleotide sequence databases which showed an average of one to two fragments generated with the enzyme combination employed ( $N c o \mathrm{I} /$ Sau3AI; see Methods). Altered expression patterns were observed for 363 fragments. Of these, $354(97.5 \%)$ were induced by $B g h$ and only $9(2.5 \%)$ were repressed by $B g h$.

The 363 differentially expressed fragments were excised from the gel, reamplified by PCR with the non-selective primers and purified. For confirmation of the cDNA-AFLP screening results, probes of the reamplified fragments were generated and hybridised to gel blots containing RNA from $B g h$ treated and untreated whole leaves 6 and $24 \mathrm{hpi}$. In these experiments, 92 cDNA-AFLP bands (approximately $25 \%$ ) resulted in pathogeninduced hybridization signals. These positive fragments were subcloned and 1-8 subclones per fragment were sequenced. The subclones of individual cDNA-AFLP fragments represented in most cases more than one sequence, indicating that a band contained mixed PCR products (Durrant et al., 2000; Zhang et al., 2003).

The sequences of all subclones were compared with each other and assembled into contiguous sequence fragments (contigs) if they exhibited an overlap of $>20$ bp with $>85 \%$ sequence identity. Surprisingly, some contigs comprised sequences of subclones from cDNA-AFLP fragments derived 
from up to 12 different selective primer combinations (data not shown). However, overlap sequence identity among clones of a contig was not always complete, indicating that such contigs likely represented more than one closely related gene. Nevertheless, cDNA-AFLP clones represented by a contig were not evaluated individually but treated as one contig in further analyses.

\section{Expression analysis of genes corresponding} to $C D N A-A F L P$ clones by microarray hybridization

Because the analysis described above showed that many excised cDNA-AFLP bands contained more than one sequence, a cDNA microarray containing 1-8 subclones of all 363 cDNA-AFLP bands was produced using previously described methods (Eisen and Brown, 1999; Reymond et al., 2000) in order to analyse the expression of the corresponding genes (see Materials and methods). The total number of subcloned cDNA-AFLP fragments spotted on the microarray was 1088 . In addition, the microarray contained 160 cDNA fragments obtained from a suppression subtractive hybridization (SSH; Diatchenko et al., 1996) screen for genes activated in powdery mildew attacked leaves after syringolin A treatment, which induces hypersensitive cell death of colonized cells (Wäspi et al., 1998; Wäspi et al., 2001). Furthermore, the microarrays contained control genes and 23 artificial genes (supplementary material, table). The positive control genes comprised 10 genes previously known to be powdery mildew-inducible, two syringolin A-inducible genes, and three BTH (benzo $[1,2,3]$ thiadiazole-7-carbothioic acid $S$-methyl ester)-inducible genes (Görlach et al., 1996). Thirty potential housekeeping wheat and barley genes as well as two human genes were included for normalization.

cDNA microarray hybridizations were carried out with probes derived from RNA of whole leaves of $B g h$-inoculated wheat 6 and 24 hpi and of corresponding uninoculated control plants, respectively. In addition, hybridization probes were prepared from the abaxial epidermis which was stripped from inoculated and control leaves, respectively, $24 \mathrm{hpi}$. These preparations were contaminated to a certain degree by adhering mesophyll cells. For simplicity, we refer to the remainder of the stripped leaves as mesophyll preparations in the following, although the adaxial epidermis was still present.
RNA from whole leaves was subjected to the indirect labelling procedure. Due to low yields of RNA from epidermal preparations, mRNA was amplified prior to the indirect labelling (Poirier and Erlander, 1998; Pàbon et al,, 2001). For consistency, both epidermis and mesophyll RNA was amplified, although sufficient total RNA from mesophyll preparations for the indirect labelling procedure was available. Hybridization signals were normalized using the control genes (see Materials and methods).

Four and six biologically independent experiments with probes of RNA derived from $B g h$-treated whole leaves were performed for the 6- and the 24-h timepoint, respectively. Experiments with probes from epidermis and mesophyll samples at the 24-hpi timepoint were performed in three biologically independent repetitions. Genes were considered significantly induced if the average hybridization signal ratio (treatment/control) was $\geq 2$ with an error probability $P<0.05$ (Student's $t$ test; see Methods). This average was taken over all individual clones represented in a contig. An overview of the number of clones/contigs that showed signal ratios of $\geq 2$ in these hybridization experiments is presented in Figure 1. In order to assess epidermis specificity of gene expression, the mesophyll contamination in epidermis preparations was estimated by using the ribulose1,5-bisphosphate carboxylase (rubisco) gene, which is exclusively expressed in cells possessing chloroplasts, as a mesophyll marker. The ratio $Q_{\mathrm{m}}$ of the mesophyll signal $\mathrm{X}_{\mathrm{m}}$ of a gene $\mathrm{X}$ and the mesophyll signal $R_{m}$ of the rubisco gene was calculated and compared to the ratio $Q_{\mathrm{e}}$ of the corresponding epidermis signal $\mathrm{X}_{\mathrm{e}}$ and the epidermis (contamination) signal $R_{\mathrm{e}}$ of rubisco transcripts. An epidermis specificity factor $\mathrm{ES}=Q_{\mathrm{e}} /$ $Q_{\mathrm{m}}$ was calculated which describes the allocation of the signal to the epidermis and the mesophyll. An ES value clearly greater than one $\left(Q_{\mathrm{e}}>Q_{\mathrm{m}}\right)$ indicates that gene $X$ was (at least also) activated in the epidermis. Thus, ES values $\geq 2$ were taken as evidence that the corresponding transcripts accumulated (also) in the epidermis.

Table 1 lists the 44 clones/contigs resulting in signal ratios (inoculated/control) $\geq 2(P<0.05)$ and $\mathrm{ES}$ values $\geq 2$, i.e. corresponding to genes whose transcripts accumulated in the epidermis $24 \mathrm{~h}$ after $B g h$ inoculation. The sequences of eight of these clones/contigs were most similar to fungal 
(A) $6 \mathrm{~h}$ post infection $(B g h)$
primary leaves

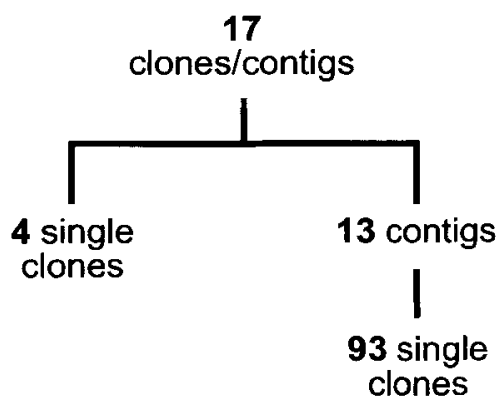

(C) $24 \mathrm{~h}$ post infection (Bgh) epidermis

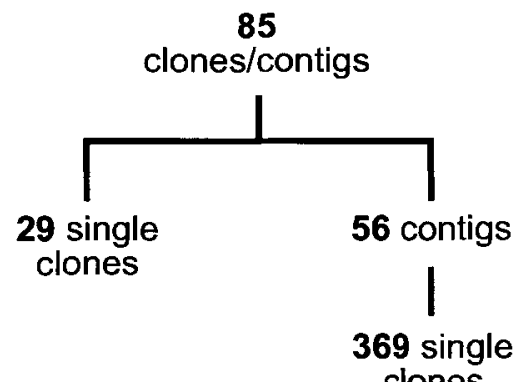

(B) $24 \mathrm{~h}$ post infection (Bgh) primary leaves

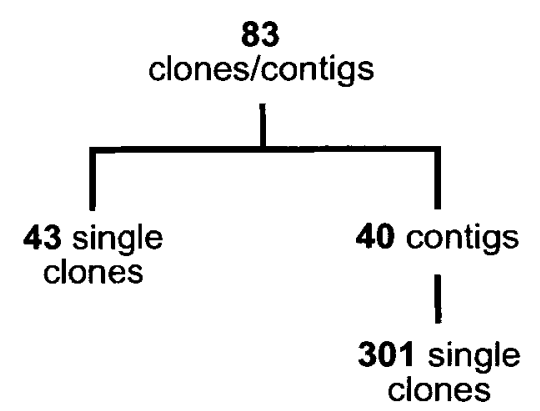

(D) $24 \mathrm{~h}$ post infection (Bgh) mesophyll

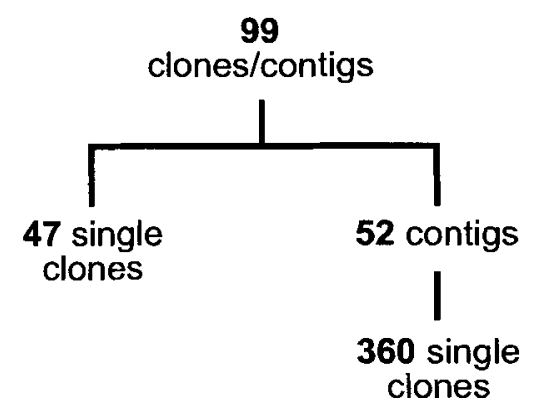

Figure 1. Overview over clones/contigs corresponding to genes induced more than twofold. The number of cDNA-AFLP and SSH clones and contigs, respectively is given corresponding to transcripts that accumulated statistically significantly at least twofold after $B h g$ inoculation as revealed by microarray hybridization experiments. The hybridization probes were derived from whole leaves at $6 \mathrm{hpi} \mathrm{(A)} \mathrm{and} 24 \mathrm{hpi} \mathrm{(B),} \mathrm{respectively,} \mathrm{or} \mathrm{from} \mathrm{epidermis} \mathrm{(C)} \mathrm{and} \mathrm{mesophyll} \mathrm{(D)} \mathrm{preparations} \mathrm{at} 24$ hpi.

sequences and therefore likely are derived from $B g h$. All of these have a transcript signal ratio $<2$ in hybridization experiments with mesophyll-derived probes. Apparently, the adaxial epidermis, which was also inoculated with $B g h$ was too minor a component in the mesophyll samples for the fungal transcripts to be reliably detected. The two clones/ contigs with no significant sequence similarity (Table 1, category, 'unknown') and with signal ratios and ES values similar to the fungal clones may therefore also be of fungal origin. All other clones/contigs either exhibit greatest sequence similarity to plant genes and/or are also expressed in the mesophyll and therefore likely represent wheat genes (Table 1). Table 2 lists the 72 clones/contigs with signal ratios $>2(P<0.05)$ and $\mathrm{ES}$ values $<2$, i.e. genes whose transcripts likely accumulate predominantly or exclusively in the mesophyll.

In the hybridization experiments with probes derived from whole leaves 6 and $24 \mathrm{hpi}, 76$ clones/contigs gave signal ratios $>2(P<0.05)$.
Of these, 51 are also listed in Table 1 or Table 2, i.e. were also detected with amplified probes derived from epidermis or mesophyll preparations. The remaining 25 clones/contigs, which are listed in Table 3, were detected only with probes obtained from whole leaves. The complete data for the 76 clones/contigs are available online as supplementary material (Table S2). A list with the accession numbers of all clones giving hybridization signal ratios $>2$ as well as their association with contigs is presented in Table S3 (supplementary material). In addition, this table contains also the gene bank accession numbers of wheat ESTs exhibiting $\geq 95 \%$ sequence identity in the overlap region and their Affymetrix gene chip accession numbers if they are included on the chip.

Verification of microarray data

The names of clones/contigs printed in boldface in Tables 1-3 originated from cDNA-AFLP bands 
Table 1. Microarray data for genes induced by Bgh predominantly in the epidermis (ES $\geq 2$ )

\begin{tabular}{|c|c|c|c|c|c|c|c|}
\hline Putative function (accession \#) & EST ID ${ }^{\mathrm{a}}$ & E-val ${ }^{b}$ & $\mathrm{ES}^{\mathrm{c}}$ & $\mathrm{Epi}^{\mathrm{d}}$ & $P \mathrm{val}^{\mathrm{e}}$ & Meso $^{d}$ & $P$ val $^{\mathrm{e}}$ \\
\hline \multicolumn{8}{|l|}{ Defense protein } \\
\hline Germin-like protein $4, T$. aestivum (AJ237942) & - & N/A & 3.5 & $31.5 \pm 4.9$ & $<0.001$ & $12.9 \pm 2.3$ & $<0.001$ \\
\hline Stress-related peroxidase, H. vulgare (AJ003141) & $\operatorname{ctg} 114$ & $7 e-06$ & 5 & $4.2 \pm 1.2$ & 0.002 & $2.2 \pm 0.2$ & $<0.001$ \\
\hline \multicolumn{8}{|l|}{ Phenolic metabolism } \\
\hline Phenylalanine ammonia-lyase, $H$. vulgare (Z49146) & etg 101 & $1 e-108$ & 2 & $3.8 \pm 0.5$ & $(0.001$ & $5.7 \pm 0.9$ & $<0.001$ \\
\hline \multicolumn{8}{|l|}{ Detoxification, redox processes } \\
\hline Alternative oxidase mRNA, T. aestivum (AF174004) & OA_a1E06 & $4 e-87$ & 12 & $2.4 \pm 0.4$ & 0.002 & $1.3 \pm 0.1$ & 0.031 \\
\hline Glutathione $S$-transferase, $A$. tauschii (AY013754) & OA_b3D05 & $9 e-22$ & 11 & $5.4 \pm 1.1$ & $<0.001$ & $2.7 \pm 0.6$ & 0.024 \\
\hline $\begin{array}{l}\text { Berberine bridge enzyme-like protein, } \\
\text { A. thaliana (Q9FK V0) }\end{array}$ & $\operatorname{ctg} \overline{5}$ & $1 \mathrm{e}-12$ & 6.4 & $7.8 \pm 1.7$ & $<0.001$ & $1.9 \pm 0.2$ & $<0.001$ \\
\hline Cytochrome P450 (CYP71E1), Sorghum bicolor (O48958) & $\operatorname{ctg} 36$ & $2 e-18$ & 4.5 & $\mathbf{5 . 4} \pm 0.7$ & $<0.001$ & $2.3 \pm 0.2$ & $<0.001$ \\
\hline $\begin{array}{l}\text { NAD-dependent formate dehydrogenase, mitochondrial } \\
\text { precursor, } H \text {. vulgare (D88272) }\end{array}$ & $\operatorname{ctg} 45$ & $1 e-63$ & 4.1 & $9.6 \pm 0.9$ & $<0.001$ & $4.9 \pm 0.3$ & $<0.001$ \\
\hline \multicolumn{8}{|l|}{ Vesicle transport } \\
\hline $\begin{array}{l}\text { Putative VAMP-associated protein, } \\
\text { A. thaliana (Q9SHC8) }\end{array}$ & $\operatorname{ctg} 99$ & $2 e-15$ & 6.7 & $15.6 \pm 2.4$ & $<0.001$ & $9.3 \pm 1.6$ & $<0.001$ \\
\hline $\begin{array}{l}\text { Small GTP-binding protein Rab (Ras-related protein), } \\
\text { Brassica campestris (U38471) }\end{array}$ & RB_339.8 & $3 e-37$ & 4.7 & $2.5 \pm 0.5$ & 0.024 & $1.4 \pm 0.3$ & 0.174 \\
\hline $\begin{array}{l}\text { Polyphosphoinositide binding protein Sshlp, } \\
\text { Glycine max (AF024651) }\end{array}$ & $\operatorname{ctg} 107$ & $4 e-51$ & 3.8 & $\mathbf{9 . 8} \pm 4.6$ & 0.008 & $5.8 \pm 2.2$ & 0.008 \\
\hline $\begin{array}{l}\text { BCS1-like/AAA-type ATPase-like protein, } \\
\text { A. thaliana (Q8LBK2) }\end{array}$ & OA_a1B08 & $5 e-38$ & 2.2 & $4.3 \pm 0.7$ & $<0.001$ & $3.7 \pm 0.5$ & $<0.001$ \\
\hline \multicolumn{8}{|l|}{ Fungal origin } \\
\hline $\begin{array}{l}\text { cDNA clone D01275 similar to retinal short-chain, } \\
\text { Bgh (AW792581) }\end{array}$ & RB_43A.5 & $1 e-107$ & 35 & $25.7 \pm 17.5$ & 0.030 & $0.9 \pm 0.1$ & 0.284 \\
\hline $\begin{array}{l}\text { Appressorium stage EST library of Bgh cDNA } \\
\text { clone A00191-R, Bgh (BM } 360927 \text { ) }\end{array}$ & $\operatorname{ctg} 22$ & $2 e-92$ & 14 & $8.7 \pm 2.3$ & $<0.001$ & $1.9 \pm 0.2$ & $<0.001$ \\
\hline Glyceraldehyde 3-phosphate dehydrogenase, Bgh (X99732) & $\operatorname{ctg} 122$ & $1 e-71$ & 11 & $7.9 \pm 3.4$ & 0.015 & $1.0 \pm 0.1$ & 0.332 \\
\hline $\begin{array}{l}\text { T4 cDNA library under conditions of nitrogen deprivation, } \\
\text { Botrytis cinerea (AL115778) }\end{array}$ & $\operatorname{ctg} 82$ & $1 e-11$ & 8.5 & $5.6 \pm 1.3$ & $<0.001$ & $1.2 \pm 0.1$ & 0.016 \\
\hline cDNA clone C00255, Bgh (AW788184) & $\operatorname{ctg} 10$ & $3 e-68$ & 7.6 & $5.9 \pm 1.8$ & $<0.001$ & $1.2 \pm 0.1$ & 0.029 \\
\hline $28 \mathrm{~S}$ ribosomal RNA gene, Neofabraea alba (AY064705) & $\operatorname{ctg} 116$ & 0 & 3.7 & $2.9 \pm 0.4$ & $<0.001$ & $1.3 \pm 0.2$ & 0.126 \\
\hline $\begin{array}{l}\text { cDNA clone D01017 similar to } S \text {-adenosyl-methionine } \\
\text { synthetase, } B g h \text { (AW792123) }\end{array}$ & RB_96.1 & $8 \mathrm{e}-86$ & 3.4 & $3.4 \pm 1.3$ & 0.044 & $1.4 \pm 0.3$ & 0.124 \\
\hline cDNA clone C01137, Bgh (AW789466) & $\operatorname{ctg} 40$ & $9 e-31$ & 3.1 & $2.5 \pm 0.5$ & 0.005 & $1.1 \pm 0.1$ & 0.365 \\
\hline \multicolumn{8}{|l|}{ Protein degradation } \\
\hline Putative subtilase, $O$. sativa $(\mathrm{Q} 8 \mathrm{~S} 1 \mathrm{H} 9)$ & $\operatorname{ctg} 46$ & $1 e-19$ & 4.3 & $2.6 \pm 0.3$ & $<0.001$ & $1.4 \pm 0.1$ & $<0.001$ \\
\hline Putative subtilase, $O$. sativa $(\mathrm{Q} 8 \mathrm{~S} 1 \mathrm{H} 8)$ & $\operatorname{ctg} 108$ & $3 e-18$ & 3.4 & $2.2 \pm 0.5$ & 0.001 & $1.4 \pm 0.1$ & 0.018 \\
\hline \multicolumn{8}{|l|}{ Kinase, receptor } \\
\hline Putative lectin-like protein kinase, $O$. sativa (Q7XIH4) & RB_78.2 & $6 e-14$ & 4 & $4.7 \pm 0.6$ & 0.004 & $2.7 \pm 0.8$ & 0.067 \\
\hline Putative receptor-like protein kinase, $O$, sativa (Q8LN27) & RB_99.2 & $1 e-03$ & 3.7 & $3.0 \pm 0.6$ & 0.019 & $1.1 \pm 0.1$ & 0.196 \\
\hline $\begin{array}{l}\text { Putative } \mathrm{LRR} \text { receptor like protein kinase, } \\
\text { O. sativa (Q8W5K7) }\end{array}$ & $\operatorname{ctg} 105$ & $2 \mathrm{e}-07$ & 2.8 & $2.6 \pm 0.9$ & 0.044 & $1.5 \pm 0.2$ & 0.028 \\
\hline \multicolumn{8}{|l|}{ Phytochrom B signalling } \\
\hline $\begin{array}{l}\text { Gigantea (GI) mRNA, T. aestivum (AF543844) } \\
\text { Transport protein }\end{array}$ & $\operatorname{ctg} 1$ & $1 \mathrm{e}-105$ & 3.9 & $21.2 \pm 1.3$ & $<0.001$ & $12.7 \pm 0.8$ & $<0.001$ \\
\hline $\begin{array}{l}\text { High affinity sulphate transporter, Allium cepa (Q8W161) } \\
\text { Diverse proteins }\end{array}$ & $\operatorname{ctg} 7$ & $2 \mathrm{e}-15$ & 2.9 & $4.6 \pm 0.4$ & $<0.001$ & $3.9 \pm 0.3$ & $<0.001$ \\
\hline 18S ribosomal RNA, Z. mays (U42796) & RB_148.2 & $2 e-40$ & 7.5 & $2.5 \pm 0.4$ & 0.015 & $1.1 \pm 0.1$ & 0.352 \\
\hline
\end{tabular}


Table 1. Continued.

\begin{tabular}{|c|c|c|c|c|c|c|c|}
\hline Putative function (accession \#) & EST ID $^{\mathrm{a}}$ & E-val ${ }^{b}$ & $\mathrm{ES}^{\mathrm{c}}$ & $\mathrm{Epi}^{\mathrm{d}}$ & $P \mathrm{val}^{\mathrm{e}}$ & Meso $^{d}$ & $P \mathrm{val}^{\mathrm{e}}$ \\
\hline \multicolumn{8}{|l|}{ Unknown } \\
\hline cDNA clone wlmk1.pk0019.g2, T. aestivum (CA662411) & RB_ 74.2 & $4 e-11$ & 8 & $6.7 \pm 1.4$ & 0.007 & $4.3 \pm 1.4$ & 0.022 \\
\hline cDNA clone:J023102L09, O. sativa (AK100543) & $\operatorname{ctg} \overline{9}$ & $8 e-17$ & 6.7 & $3.7 \pm 0.6$ & $<0.001$ & $1.2 \pm 0.1$ & 0.004 \\
\hline Wheat EST BQ162027 & a3A04 & $2 e-86$ & 5.7 & $28.5 \pm 5.9$ & $<0.001$ & $7.4 \pm 1.3$ & $<0.001$ \\
\hline EST, clone $11815 \mathrm{R}$, Triticum turgidum (AJ615560) & RB_96.2 & $2 e-15$ & 3.7 & $\mathbf{6 . 0} \pm 0.9$ & 0.004 & $4.2 \pm 0.9$ & 0.011 \\
\hline Wheat EST CA668159 & RB_78.3 & $3 e-34$ & 3.7 & $4.2 \pm 1.2$ & 0.032 & $1.9 \pm 0.5$ & 0.125 \\
\hline Chromosome 10 , section 37 of 77, o. sativa (AE017083) & $\operatorname{ctg} 59$ & $1 e-04$ & 3.7 & $3.0 \pm 0.4$ & $<0.001$ & $1.7 \pm 0.1$ & $<0.001$ \\
\hline No significant homology & RB_12.1 & $\mathrm{N} / \mathrm{A}$ & 3.6 & $3.0 \pm 0.6$ & 0.022 & $\mathbf{2 . 0} \pm 0.2$ & 0.015 \\
\hline Wheat EST CA669769 & $\operatorname{ctg} 37$ & $1 \mathrm{e}-102$ & 2.8 & $5.8 \pm 0.8$ & $<0.001$ & $2.7 \pm 0.3$ & $<0.001$ \\
\hline Wheat EST CD883151 & RB_255.8 & $1 e-43$ & 2.8 & $2.0 \pm 0.4$ & 0.046 & $0.9 \pm 0.0$ & 0.094 \\
\hline Wheat EST CA705231 & RB_153.2 & $8 e-37$ & 2.7 & $2.3 \pm 0.8$ & 0.079 & $\mathbf{2 . 0} \pm 0.4$ & 0.032 \\
\hline Wheat EST CA686488 & $\operatorname{ctg} 13$ & $2 e-37$ & 2.5 & $8.3 \pm 1.7$ & $<0.001$ & $4.8 \pm 0.9$ & $<0.001$ \\
\hline $\begin{array}{l}\text { BAC clone: OSJNBa0007H12, genomic DNA, } \\
\text { O. sativa (AP004990) }\end{array}$ & $\operatorname{ctg} 16$ & $4 e-10$ & 2.3 & $2.9 \pm 0.5$ & $<0.001$ & $1.6 \pm 0.1$ & $<0.001$ \\
\hline No significant homology & OA_b2E03 & $N / A$ & 2.2 & $2.9 \pm 0.3$ & $<0.001$ & $2.9 \pm 0.2$ & $<0.001$ \\
\hline Wheat EST CD 93390 & RB_164.4 & $3 e-34$ & 2.2 & $2.2 \pm 0.9$ & 0.120 & $2.1 \pm 0.3$ & 0.021 \\
\hline No significant homology & $\operatorname{ctg} 62$ & $\mathrm{~N} / \mathrm{A}$ & 2.1 & $2.1 \pm 0.4$ & 0.002 & $1.6 \pm 0.3$ & 0.029 \\
\hline No significant homology & OA_b1A06 & $N / A$ & 2.1 & $2.0 \pm 0.3$ & 0.021 & $0.9 \pm 0.0$ & 0.144 \\
\hline
\end{tabular}

${ }^{a}$ Clones/contigs in boldface revealed transcript accumulation in RNA gel blot hybridizations. Accession numbers of clones are listed in table S3 (supplementary material).

${ }^{b}$ Blast hit E-value.

c Epidermis specificity factor.

${ }^{d}$ Hybridization signal ratio obtained with probes from $B g h$ inoculated and control epidermis (Epi) and mesophyll (Meso) preparations, respectively. Ratios $\geq 2$ are in boldface.

${ }^{e} P$ values indicate the significant difference of the mean $\log _{2}$-transformed ratios of challenged plants over ratio one in three independent experiments.

which resulted in hybridization signals accumulating after powdery mildew inoculation when used as probes in RNA gel blot hybridizations (see above; data not shown). Although a cDNA-AFLP band may have contained more than one sequence, the fact that subclones from these bands also detected accumulating transcripts in the microarray hybridization experiments is consistent with the RNA gel blot hybridization results and corroborates the microarray data.

In addition, the microarray hybridization data were verified by quantitative RT-PCR for seven transcripts accumulating strongly in the epidermis after Bgh inoculation. PCR was performed in the presence of ${ }^{33} \mathrm{P}-\alpha-\mathrm{dCTP}$ and aliquots were taken after $19,22,25,28$, and 31 cycles using actin as a standard. These products were separated on nondenaturing polyacrylamide gels, exposed to phosphor screens and signals were quantified using OptiQuant software (Perkin-Elmer). The values were normalized using a calibration curve calculated from the actin standard (see Methods). Since a contamination of epidermis preparations with mesophyll cells was not avoidable, the signal of the mesophyll marker rubisco was used to calculate the epidermal and mesophyll portion of the signal of a probe, as described above. The results obtained (Figure 2) were very similar to the microarray data obtained for these clones, confirming the reliability of the microarray hybridization results.

\section{Discussion}

\section{Microarray hybridization analysis}

Two different labelling methods were used to generate fluorescent probes. If enough total RNA was available, i.e. if RNA was extracted from total leaves, mRNA was isolated and subjected to the standard, indirect labelling method. If only limited amounts of total RNA were available, i.e. if RNA was extracted from the epidermis and the mesophyll, the RNA was amplified using T7-RNA polymerase prior to standard labelling. This amplification step may distort the relative abundance of individual RNA species, although there 
Table 2. Microarray data for genes induced by $B g h$ predominantiy in the mesophyll $(\mathrm{ES}<2)$.

\begin{tabular}{|c|c|c|c|c|c|c|c|}
\hline Putative function (accession \#) & EST ID ${ }^{\mathrm{a}}$ & E-val ${ }^{b}$ & $\mathrm{ES}^{\mathrm{c}}$ & Epi $^{\mathrm{d}}$ & $P \mathrm{val}^{\mathrm{e}}$ & Meso $^{\text {d }}$ & $P \mathrm{val}^{\mathrm{e}}$ \\
\hline \multicolumn{8}{|l|}{ Defense protein } \\
\hline$\beta \sim 1,3$-Endoglucanase, T. aestivum (Y18212) & $\operatorname{ctg} 15$ & $1 e-140$ & 0.9 & $8.5 \pm 0.7$ & $<0.001$ & $21.0 \pm 1.4$ & $<0.001$ \\
\hline$\beta$-1,3-Endoglucanase, $T$. aestivum (Y18212) & ctg 69 & $1 \mathrm{e}-83$ & 0.8 & $\mathbf{7 . 5} \pm 0.7$ & $<0.001$ & $25.2 \pm 1.0$ & $<0.001$ \\
\hline$\beta$-1,3-Endoglucanase, $T$. aestivum (Y18212) & $\operatorname{ctg} 91$ & $1 e-100$ & 0.9 & $6.0 \pm 0.5$ & $<0.001$ & $12.0 \pm 0.9$ & $<0.001$ \\
\hline Thaumatin-like protein TLP4, H. vulgare (AF355455) & $\operatorname{ctg} 83$ & $7 e-46$ & 1 & $4.4 \pm 1.1$ & $<0.001$ & $12.1 \pm 3.4$ & $<0.001$ \\
\hline$\beta$-1,3-glucanase, $T$. aestivum (AF112965) & $\operatorname{ctg} 79$ & le-111 & 0.5 & $4.2 \pm 1.5$ & 0.009 & $\mathbf{1 8 . 1} \pm 6.3$ & 0.010 \\
\hline Pathogenesis related protein $1.1, T$. aestivum (AJ007348) & $\operatorname{ctg} 72$ & $1 e-73$ & 0.5 & $3.2 \pm 0.8$ & $<0.001$ & $8.9 \pm 1.6$ & $<0.001$ \\
\hline Thaumatin-like protein, T. aestivum (X58394) & ctg 85 & $2 e-66$ & 0.6 & $\mathbf{3 . 0} \pm 0.5$ & $<0.001$ & $7.6 \pm 0.7$ & $<0.001$ \\
\hline $\begin{array}{l}\text { Pathogenic related protein in response to } \\
B g h, H . \text { vulgare (Y10813) }\end{array}$ & $\operatorname{ctg} 39$ & $6 e-08$ & 1.3 & $2.5 \pm 0.2$ & $<0.001$ & $2.8 \pm 0.3$ & $<0.001$ \\
\hline Thaumatin-like protein TLP8, H. vulgare (AF355458) & $\operatorname{ctg} 18$ & $4 e-08$ & 1.1 & $2.3 \pm 0.4$ & $<0.001$ & $3.4 \pm 0.4$ & $<0.001$ \\
\hline$\beta$-1,3-Endoglucanase, $T$. aestivum (Y 18212) & $\operatorname{ctg} 6$ & $3 e-28$ & 0.5 & $\mathbf{2 . 0} \pm 0.4$ & 0.009 & $6.5 \pm 0.7$ & $<0.001$ \\
\hline WCI-5, $T$, aestivum (U32431) & RB_360.4 & $1 e-109$ & 1.3 & $1.8 \pm 0.4$ & 0.064 & $3.5 \pm 0.3$ & 0.003 \\
\hline Germin 9f-2.8 gene, T. aestivum (M63223) & $\operatorname{ctg} 57$ & $3 e-73$ & 0.5 & $1.7 \pm 0.2$ & 0.039 & $5.4 \pm 0.8$ & $<0.001$ \\
\hline $\begin{array}{l}\text { NBS-LRR disease resistance protein homologue, } \\
\text { H. vulgare (AJ507096) }\end{array}$ & OA_a1E08 & $4 e-51$ & 1 & $1.7 \pm 0.4$ & 0.035 & $2.2 \pm 0.7$ & 0.012 \\
\hline Superoxide dismutase-4A, Z. mays (X17564) & $\operatorname{ctg} 64$ & $3 e-22$ & 0.8 & $1.3 \pm 0.1$ & 0.059 & $3.3 \pm 0.3$ & $<0.001$ \\
\hline Chitinase II (PR-3), H. vulgare (AJ276226) & $\operatorname{ctg} 28$ & $6 e-22$ & 0.8 & $1.3 \pm 0.1$ & $<0.001$ & $2.5 \pm 0.1$ & $<0.001$ \\
\hline \multicolumn{8}{|l|}{ Phenolic metabolism } \\
\hline Cinnamyl alcohol dehydrogenase, Lolium multiflorum & $\operatorname{ctg} 98$ & $1 e-57$ & 1.5 & $2.6 \pm 0.1$ & $<0.001$ & $2.2 \pm 0.4$ & $<0.001$ \\
\hline \multicolumn{8}{|l|}{ Detoxification, redox processes } \\
\hline Put. glutathione $S$-transferase, $T$. aestivum (BT009348) & $\operatorname{ctg} 17$ & $2 e-25$ & 1.6 & $4.2 \pm 0.4$ & $<0.001$ & $\mathbf{5 . 0} \pm 0.6$ & $<0.001$ \\
\hline NADH dehydrogenase, S. tuberosum (AJ245862) & OA_a2B11 & $5 e-62$ & 1.1 & $2.7 \pm 0.3$ & $<0.001$ & $3.3 \pm 0.6$ & 0.010 \\
\hline \multicolumn{8}{|l|}{ Abiotic stress } \\
\hline Chaperonin hsp60, Z. mays (L21006) & OA_b1C09 & $8 \mathrm{e}-40$ & 1.1 & $1.4 \pm 0.3$ & 0.261 & $5.2 \pm 1.6$ & 0.006 \\
\hline HSP70, P. Sativum (X54739) & OA_a3B09 & $8 \mathrm{e}-48$ & 0.9 & $0.8 \pm 0.1$ & $<0.001$ & $2.9 \pm 0.6$ & $<0.001$ \\
\hline \multicolumn{8}{|l|}{ Vesicle transport } \\
\hline Put. Membrane associated protein, A. thaliana (AY096741) & $\operatorname{ctg} 4$ & $1 e-07$ & 1.7 & $2.2 \pm 0.2$ & $<0.001$ & $1.9 \pm 0.1$ & $<0.001$ \\
\hline \multicolumn{8}{|l|}{ Protein degradation } \\
\hline Subtilisin-chymotrypsin inhibitor $2, H$. vulgare (Y08625) & $\operatorname{ctg} 29$ & $3 e-24$ & 1.8 & $6.7 \pm 0.4$ & $<0.001$ & $\mathbf{1 5 . 5} \pm 0.9$ & $<0.001$ \\
\hline Lon protease homolog 1, Z. mays (Q8GV57) & RB_216A.4 & $8 \mathrm{e}-19$ & 1.2 & $2.7 \pm 0.9$ & 0.090 & $2.2 \pm 0.5$ & 0.044 \\
\hline Alpha subunit of $20 \mathrm{~S}$ proteasome, O. sativa (Q9LSU1) & OA_b1G05 & $2 e-42$ & 0.3 & $0.9 \pm 0.2$ & 0.224 & $\mathbf{3 . 0} \pm 0.5$ & $<0.001$ \\
\hline \multicolumn{8}{|l|}{ Kinase, receptor } \\
\hline $\begin{array}{l}\text { Similar to wak4 (wall-associated kinase), } \\
\text { A. thaliana (Q9LWG6) }\end{array}$ & $\operatorname{ctg} 52$ & $1 e-08$ & 1.5 & $9.1 \pm 1.4$ & $<0.001$ & $6.1 \pm 0.5$ & $<0.001$ \\
\hline Putative histidine kinase, $O$. sativa $(\mathrm{Q} 852 \mathrm{H} 8)$ & $\operatorname{ctg} 33$ & $7 e-21$ & 0.9 & $1.7 \pm 0.2$ & $<0.001$ & $3.3 \pm 0.7$ & $<0.001$ \\
\hline Leucine-rich-like protein, Aegilops tauschii (Q8LKV9) & RB_286.2 & $1 e-14$ & 1 & $1.4 \pm 0.3$ & 0.162 & $2.4 \pm 0.3$ & 0.010 \\
\hline \multicolumn{8}{|l|}{ Transcription factor } \\
\hline Myb-related protein, O. sativa (Q7XBH4) & RB_226.2 & $7 e-09$ & 1.3 & $1.6 \pm 0.6$ & 0.227 & $2.0 \pm 0.3$ & 0.014 \\
\hline \multicolumn{8}{|l|}{ Transport } \\
\hline Sec61 alpha subunit, $H$. vulgare (AY044237) & $\operatorname{ctg} 121$ & $3 e-34$ & 0.8 & $4.9 \pm 1.1$ & 0.003 & $9.8 \pm 2.1$ & $<0.001$ \\
\hline $\begin{array}{l}\text { UDP-galactose/UDP-glucose transporter, } \\
A, \text { thaliana (AY115566) }\end{array}$ & $\operatorname{ctg} 53$ & $5 e-88$ & 0.5 & $2.6 \pm 0.1$ & $<0.001$ & $\mathbf{4 . 0} \pm 0.2$ & $<0.001$ \\
\hline Put. peptide transporter protein, $H$. vulgare (AJ495773) & $\operatorname{ctg} 21$ & $1 e-33$ & 1.9 & $2.1 \pm 0.3$ & $<0.001$ & $1.6 \pm 0.2$ & $<0.001$ \\
\hline \multicolumn{8}{|l|}{ Glycosylation } \\
\hline $\begin{array}{l}\text { Putative immediate-early salicylate-induced } \\
\text { glucosyltransferase, } O \text {. sativa }(\mathrm{Q} 84 \mathrm{M} 46)\end{array}$ & $\operatorname{ctg} 48$ & $2 e-29$ & 1.1 & $\mathbf{3 5 . 3} \pm 5.6$ & $<0.001$ & $34.2 \pm 4.2$ & $<0.001$ \\
\hline Cis-zeatin $O$-glucosyltransferase, $Z$. mays (Q8S465) & $\operatorname{ctg} 27$ & $3 e-10$ & 1.7 & $2.8 \pm 0.4$ & $<0.001$ & $3.3 \pm 0.5$ & $<0.001$ \\
\hline
\end{tabular}


Table 2. Continued.

\begin{tabular}{|c|c|c|c|c|c|c|c|}
\hline Putative function (accession \#) & EST ID I $^{\mathrm{a}}$ & E-val ${ }^{b}$ & $\mathrm{ES}^{\mathrm{c}}$ & $\mathrm{Epi}^{\mathrm{d}}$ & $P \mathrm{val}^{\mathrm{e}}$ & Meso $^{\mathrm{d}}$ & $P$ val $^{\mathrm{e}}$ \\
\hline \multicolumn{8}{|l|}{ Diverse processes } \\
\hline PIR7a and PIR7b genes, $O$. sativa $(\mathrm{Z} 34271)$ & $\operatorname{ctg} 58$ & $3 e-23$ & 1.4 & $3.9 \pm 1.0$ & $<0.001$ & $3.6 \pm 0.6$ & $<0.001$ \\
\hline Putative myosin-like protein, $A$. thaliana (AK118721) & RB_226.3 & $6 e-17$ & 0.9 & $3.8 \pm 0.5$ & 0.005 & $9.7 \pm 1.7$ & 0.004 \\
\hline Kaurene synthase, Z. mays (AF105149) & $\operatorname{ctg} 47$ & $1 e-20$ & 1.8 & $2.7 \pm 0.5$ & $<0.001$ & $2.8 \pm 0.3$ & $<0.001$ \\
\hline $\begin{array}{l}\text { 3-phosphoshikimate 1-carboxyvinyltransferase, } \\
\text { Z. mays (Q946U9) }\end{array}$ & $\operatorname{ctg} 119$ & $7 e-21$ & 0.8 & $2.3 \pm 0.3$ & $<0.001$ & $4.2 \pm 0.6$ & $<0.001$ \\
\hline 2-oxoglutarate dehydrogenase, $A$. thaliana (AJ223802) & OA_a3B02 & le-103 & 1.7 & $2.1 \pm 0.2$ & $<0.001$ & $1.3 \pm 0.1$ & 0.065 \\
\hline Calreticulin (CRH2), H. vulgare (L27349) & $\operatorname{ctg} 44$ & $1 e-40$ & 0.6 & $\mathbf{2 . 0} \pm 0.2$ & $<0.001$ & $5.9 \pm 1.0$ & $<0.001$ \\
\hline Calreticulin (CRH2), H. vulgare (L27349) & $\operatorname{ctg} 14$ & le -169 & 1.1 & $\mathbf{2 . 0} \pm 0.2$ & $<0.001$ & $3.9 \pm 0.6$ & $<0.001$ \\
\hline Calreticulin (CRH2), H. vulgare (L27349) & OA_b2C03 & $1 e-105$ & 1.4 & $1.9 \pm 0.4$ & 0.010 & $4.8 \pm 1.6$ & 0.033 \\
\hline $\begin{array}{l}\text { d-TDP-glucose dehydratase, Phragmites australis } \\
\text { (AJ295156) }\end{array}$ & $\mathrm{OA} \_\mathrm{a} 2 \mathrm{H} 02$ & $1 \mathrm{e}-109$ & 0.6 & $1.5 \pm 0.2$ & 0.003 & $\mathbf{4 . 0} \pm 0.9$ & 0.003 \\
\hline Pir7b, O. sativa $(\mathrm{Z} 34270)$ & OA_b2A07 & le-7l & 0.6 & $1.4 \pm 0.2$ & 0.105 & $3.5 \pm 0.6$ & $<0.001$ \\
\hline Cyclophilin, T. aestivum (AY290733) & RB_244.2 & $6 e-49$ & 0.8 & $1.4 \pm 0.2$ & 0.082 & $3.3 \pm 0.7$ & 0.023 \\
\hline Elongation factor 1 alpha-subunit, T. aestivum (M90077) & $\operatorname{ctg} \overline{6} 6$ & $2 e-67$ & 1.3 & $1.4 \pm 0.1$ & 0.006 & $2.6 \pm 0.4$ & $<0.001$ \\
\hline Citrate synthase, O. sativa (AF302906) & OA_b1H11 & $1 e-90$ & 1.4 & $1.4 \pm 0.2$ & 0.029 & $2.0 \pm 0.2$ & $<0.001$ \\
\hline $\begin{array}{l}\text { Put. GDP-mannose pyrophosphorylase, } O \text {. sativa } \\
\text { (AP004705) }\end{array}$ & RB_327.3 & $7 e-56$ & 1.2 & $1.3 \pm 0.3$ & 0.286 & $2.2 \pm 0.4$ & 0.023 \\
\hline $\begin{array}{l}\text { 60S ribosomal protein L10-2 (putative tumor suppressor } \\
\text { SG12), O. sativa ( } \mathrm{P} 45636)\end{array}$ & $\operatorname{ctg} 117$ & $9 e-14$ & 1.2 & $1.2 \pm 0.1$ & $<0.001$ & $2.6 \pm 0.4$ & $<0.001$ \\
\hline Cytosolic GAPDH, T. aestivum (AF251217) & OA_b3C10 & $4 e-89$ & 1 & $1.2 \pm 0.1$ & 0.154 & $2.2 \pm 0.5$ & 0.046 \\
\hline $60 \mathrm{~S}$ ribosomal protein $\mathrm{L} 12, A$. thaliana $(\mathrm{T} 45883)$ & RB_50.4 & $6 e-36$ & 1.3 & $1.1 \pm 0.1$ & 0.302 & $2.0 \pm 0.3$ & 0.026 \\
\hline Pir7b, O. sativa $(\mathrm{Z} 34271)$ & OA_b1B01 & $5 e-80$ & 0.6 & $1.0 \pm 0.1$ & 0.448 & $\mathbf{3 . 0} \pm 0.5$ & $<0.001$ \\
\hline \multicolumn{8}{|l|}{ Unknown } \\
\hline Osr40g3 protein, O. sativa (Y08988) & RB_282.5 & $3 e-04$ & 0.7 & $12.8 \pm 3.2$ & 0.004 & $27.0 \pm 4.8$ & 0.002 \\
\hline Wheat EST CD873563 & $\operatorname{ctg} 25$ & $1 \mathrm{e}-114$ & 1.8 & $\mathbf{6 . 0} \pm 0.5$ & $<0.001$ & $\mathbf{1 1 . 3} \pm 1.2$ & $<0.001$ \\
\hline $\begin{array}{l}\text { BAC clone:OJ1513_F02, genomic DNA, } \\
\text { o. sativa (AP005244) }\end{array}$ & RB_190.3 & $4 e-03$ & 1.6 & $\mathbf{3 . 8} \pm 0.2$ & $<0.001$ & $5.2 \pm 0.4$ & $<0.001$ \\
\hline No significant homology & RB_107.2 & $\mathrm{N} / \mathrm{A}$ & 1.9 & $3.7 \pm 1.5$ & 0.048 & $3.6 \pm 0.9$ & 0.018 \\
\hline No significant homology & $\operatorname{ctg} 115$ & N/A & 1 & $3.2 \pm 0.3$ & $<0.001$ & $4.9 \pm 0.4$ & $<0.001$ \\
\hline Wheat EST BQ902295 & $\operatorname{ctg} 123$ & $2 e-24$ & 0.9 & $2.6 \pm 0.4$ & 0.003 & $3.9 \pm 0.7$ & 0.002 \\
\hline cDNA clone:001-109-C01, O. sativa (AK062944) & $\operatorname{ctg} 118$ & $2 \mathrm{e}-03$ & 1.2 & $2.5 \pm 0.5$ & 0.002 & $6.1 \pm 2.2$ & 0.003 \\
\hline No significant homology & $\operatorname{ctg} 120$ & $\mathrm{~N} / \mathrm{A}$ & 0.7 & $2.5 \pm 0.5$ & 0.010 & $5.6 \pm 0.9$ & $<0.001$ \\
\hline No significant homology & RB_182.5 & $\mathrm{N} / \mathrm{A}$ & 0.4 & $2.1 \pm 0.0$ & $<0.001$ & $4.8 \pm 0.9$ & 0.007 \\
\hline CDNA clone:J013161I06, O. sativa (AK072199) & $\operatorname{ctg} 94$ & $5 e-21$ & 1.2 & $2.0 \pm 0.3$ & $<0.001$ & $3.6 \pm 0.8$ & $<0.001$ \\
\hline No significant homology & $\operatorname{ctg} 80$ & $\mathrm{~N} / \mathrm{A}$ & 1.2 & $1.7 \pm 0.3$ & 0.004 & $2.4 \pm 0.4$ & $<0.001$ \\
\hline No significant homology & RB_151.1 & $\mathrm{N} / \mathrm{A}$ & 0.8 & $1.5 \pm 0.5$ & 0.211 & $2.4 \pm 0.7$ & 0.044 \\
\hline $\begin{array}{l}\text { BAC clone: OSJNBb0091E11, genomic DNA, } \\
\text { O. sativa (AL606629) }\end{array}$ & $\operatorname{ctg} 42$ & $1 \mathrm{e}-10$ & 1 & $1.5 \pm 0.2$ & 0.007 & $2.1 \pm 0.3$ & $<0.001$ \\
\hline No significant homology & RB_182.1 & $\mathrm{N} / \mathrm{A}$ & 0.6 & $1.5 \pm 0.2$ & 0.069 & $2.0 \pm 0.4$ & 0.038 \\
\hline Wheat EST CA642908 & $\operatorname{ctg} 88$ & $4 e-68$ & 0.5 & $1.4 \pm 0.1$ & 0.011 & $2.0 \pm 0.5$ & 0.031 \\
\hline Hypothetical protein, A. thaliana (Q8RXU1) & OA_b2F09 & $2 e-26$ & 1.5 & $1.3 \pm 0.2$ & 0.016 & $2.1 \pm 0.4$ & 0.020 \\
\hline $\begin{array}{l}\text { PAC clone:P0684C01, genomic DNA, } O \text {. sativa } \\
\text { (AP002487) }\end{array}$ & $\operatorname{ctg} \overline{100}$ & $6 e-23$ & 1.1 & $1.2 \pm 0.1$ & 0.193 & $3.1 \pm 0.4$ & $<0.001$ \\
\hline No significant homology & RB_164.1 & $\mathrm{N} / \mathrm{A}$ & 1.5 & $1.2 \pm 0.4$ & 0.348 & $2.3 \pm 0.1$ & 0.002 \\
\hline cDNA clone HRO4453_F10_L19, O. sativa (CN817762) & $\operatorname{ctg} \overline{7} 7$ & $1 e-22$ & 0.8 & $1.2 \pm 0.3$ & 0.360 & $\mathbf{2 . 0} \pm 0.2$ & $<0.001$ \\
\hline Wheat EST BE517301 & RB_38B.3 & $3 e-23$ & 0.5 & $1.0 \pm 0.2$ & 0.084 & $2.5 \pm 0.5$ & 0.006 \\
\hline $\begin{array}{l}\text { GDSL-motif lipase/hydrolase-like, clone } \\
\text { wlm24.pk0027.a6:fis, T. aestivum (BT009331) }\end{array}$ & $\operatorname{ctg} 49$ & $1 e-19$ & 0.9 & $0.6 \pm 0.0$ & $<0.001$ & $\mathbf{2 . 0} \pm 0.1$ & $<0.001$ \\
\hline
\end{tabular}

${ }^{a}$ Clones/contigs in boldface revealed transcript accumulation in RNA gel blot hybridizations.

${ }^{b}$ Blast hit E-value.

${ }^{\mathrm{C}}$ Epidermis specificity factor.

d Hybridization signal ratio obtained with probes from $\mathrm{Bgh}$ inoculated and control epidermis (Epi) and mesophyll (Meso) preparations, respectively. Ratios $\geq 2$ are in boldface.

e $P$ values indicate the significant difference of the mean $\log _{2}$-transformed ratios of challenged plants over ratio one in three independent experiments. 
Table 3. Microarray data for induced genes exclusively detected in whole leaves 6 and $24 \mathrm{~h}$ after inoculation with $B g h$.

\begin{tabular}{|c|c|c|c|c|c|c|}
\hline Putative function (accession \#) & EST ID ${ }^{a}$ & E-val ${ }^{b}$ & $6 \mathrm{hpi}$ & $P \mathrm{val}^{\mathrm{c}}$ & 24 hpi & $P \mathrm{val}^{\mathrm{C}}$ \\
\hline \multicolumn{7}{|l|}{ Defense protein } \\
\hline$\beta$-1,3-Glucanase (GLU2) gene, $H$. vulgare (M91814) & $\operatorname{ctg} 26$ & $1 \mathrm{e}-52$ & $1.7 \pm 0.3$ & 0.022 & $4.7 \pm 1.2$ & $<0.001$ \\
\hline $\begin{array}{l}\text { NBS-LRR disease resistance protein homologue, } \\
\text { H. vulgare (Q84KD0) }\end{array}$ & $\operatorname{ctg} 12$ & $8 \mathrm{e}-04$ & $1.0 \pm 0.0$ & 0.274 & $2.0 \pm 0.2$ & $<0.001$ \\
\hline beta-glucanase, barley ( $\mathbf{S} 35156)$ & RB_24.4 & $4 e-5$ & $1.0 \pm 0.1$ & 0.419 & $2.0 \pm 0.3$ & 0.003 \\
\hline \multicolumn{7}{|l|}{ Phenolic metabolism } \\
\hline Phenylalanine ammonia-lyase, $H$. vulgare (Z49146) & $\operatorname{ctg} 11$ & $1 e-43$ & $1.0 \pm 0.0$ & 0.349 & $2.6 \pm 0.3$ & $<0.001$ \\
\hline \multicolumn{7}{|l|}{ Oxidative burst, detoxification } \\
\hline $\begin{array}{l}\text { Putative NADPH-dependent oxidoreductase, } \\
\text { P. somniferum (Q9SQ64) }\end{array}$ & $\mathrm{OA} \_\mathrm{a} 2 \mathrm{C} 02$ & $2 \mathrm{e}-15$ & $1.6 \pm 0.2$ & 0.015 & $3.1 \pm 0.4$ & $<0.001$ \\
\hline Putative cytochrome P450 (CYP87), O. sativa (Q7XU41) & $\operatorname{ctg} 70$ & $4 e-44$ & $1.1 \pm 0.0$ & 0.037 & $3.6 \pm 0.1$ & $<0.001$ \\
\hline \multicolumn{7}{|l|}{ Abiotic stress } \\
\hline Hsp23.5, T. aestivum (AF104107) & OA_alB01 & $3 e-34$ & $2.1 \pm 0.4$ & 0.006 & $2.6 \pm 0.3$ & $<0.001$ \\
\hline Hsp23.6, T. aestivum (AF104108) & OA_alH02 & $2 e-88$ & $1.4 \pm 0.2$ & 0.015 & $2.5 \pm 0.5$ & $<0.001$ \\
\hline \multicolumn{7}{|l|}{ Protein degradation } \\
\hline Ubiquitin-conjugating enzyme (UBC), H. vulgare (AY220735) & RB_178.8 & $6 e-10$ & $1.4 \pm 0.3$ & 0.091 & $5.4 \pm 0.8$ & $<0.001$ \\
\hline \multicolumn{7}{|l|}{ Kinase, receptor } \\
\hline Putative wall-associated kinase $2, O$. sativa (Q9ARV3) & $\operatorname{ctg} 104$ & $5 e-09$ & $1.3 \pm 0.1$ & 0.001 & $2.9 \pm 0.3$ & $<0.001$ \\
\hline \multicolumn{7}{|l|}{ Diverse proteins } \\
\hline Putative aspartate aminotransferase, O.sativa (Q943I5) & RB_218.2 & $8 e-16$ & $1.4 \pm 0.4$ & 0.175 & $2.2 \pm 0.3$ & 0.002 \\
\hline Adenylate kinase-d, $O$, sativa $(\mathrm{Q} 08479)$ & OA_a3A08 & $3 e-32$ & $1.2 \pm 0.1$ & 0.118 & $3.2 \pm 0.3$ & $<0.001$ \\
\hline Prohibitin, Z. mays (AF236371) & OA_a3C03 & $1 \mathrm{e}-114$ & $1.1 \pm 0.1$ & 0.279 & $4.7 \pm 1.0$ & $<0.001$ \\
\hline Alanine aminotransferase (patent), H. vulgare (Z26322) & $\mathrm{OA}_{-} \mathrm{a} 2 \mathrm{D} 10$ & $3 \mathrm{e}-99$ & $1.1 \pm 0.1$ & 0.263 & $2.7 \pm 0.4$ & $<0.001$ \\
\hline $\begin{array}{l}\text { Glucose-6-phosphate isomerase-like } \\
\text { protein, } O \text {. sativa (AY224509) }\end{array}$ & RB_291.4 & $5 e-46$ & $1.1 \pm 0.1$ & 0.132 & $2.1 \pm 0.2$ & $<0.001$ \\
\hline Phosphoglycerate mutase, $T$. aestivum (AF475111) & OA_b2G09 & 0 & $1.0 \pm 0.1$ & 0.405 & $2.3 \pm 0.2$ & $<0.001$ \\
\hline Cytoplasmatic aconitate hydratase, $A$. thaliana (AY136414) & OA_b3G05 & $4 e-48$ & $1.0 \pm 0.1$ & 0.385 & $2.2 \pm 0.1$ & $<0.001$ \\
\hline $\begin{array}{l}\text { ADP forming succinate-CoA ligase b-chain, } \\
\text { A. thaliana (AY099707) }\end{array}$ & OA_b1D01 & $3 e-77$ & $0.9 \pm 0.1$ & 0.024 & $2.3 \pm 0.3$ & $<0.001$ \\
\hline Succinyl-CoA-ligase beta subunit, $A$, thaliana (AJ001808) & OA_blEll & $5 e-46$ & $0.8 \pm 0.1$ & 0.007 & $2.2 \pm 0.2$ & $<0.001$ \\
\hline \multicolumn{7}{|l|}{ Unknown } \\
\hline No significant homology & RB_104.3 & $\mathrm{N} / \mathrm{A}$ & $1.4 \pm 0.2$ & 0.035 & $2.6 \pm 0.4$ & 0.002 \\
\hline cDNA clone:J013165K20, O. sativa (AK072222) & $\operatorname{ctg} 41$ & $7 e-04$ & $1.3 \pm 0.1$ & 0.009 & $2.9 \pm 0.5$ & $<0.001$ \\
\hline Wheat EST BE413608 & $\operatorname{ctg} 103$ & $4 e-11$ & $1.1 \pm 0.1$ & 0.086 & $3.1 \pm 0.4$ & $<0.001$ \\
\hline Wheat EST CD883425 & OA_blH08 & $2 \mathrm{e}-58$ & $1.1 \pm 0.1$ & 0.155 & $2.3 \pm 0.3$ & $<0.001$ \\
\hline Wheat EST BT009374.1 & $\mathrm{OA} b 3 \mathrm{C} 12$ & 0 & $1.0 \pm 0.1$ & 0.437 & $2.0 \pm 0.2$ & $<0.001$ \\
\hline Wheat EST BF484342 & OA b3E09 & $2 \mathrm{e}-31$ & $0.9 \pm 0.1$ & 0.131 & $2.4 \pm 0.3$ & $<0.001$ \\
\hline
\end{tabular}

${ }^{\text {a }}$ Clones/contigs in boldface revealed transcript accumulation in RNA gel blot hybridizations. Accession numbers of clones are listed in table S3 (supplementary material).

${ }^{b}$ Blast hit E-value.

${ }^{c} P$ values indicate the significant difference of the mean $\log _{2}$-transformed ratios of challenged plants over ratio one in four and six independent experiments for the 6-and 24-h timepoint, respectively.

are many reports showing that this method is to be preferred over other amplification methods (Poirier and Erlander, 1998; Pábon et al., 2001). However, comparing the results obtained from microarrays hybridised with probes labelled with different methods revealed that firstly, the sets of genes detected as being up-regulated were not identical, and secondly, that the ratios between control and treatment signals of transcripts detected with both methods showed differences. Nevertheless, the positive and the negative control genes showed the expected up-regulation and ratios around one, respectively, and thus, both methods delivered reliable results. 


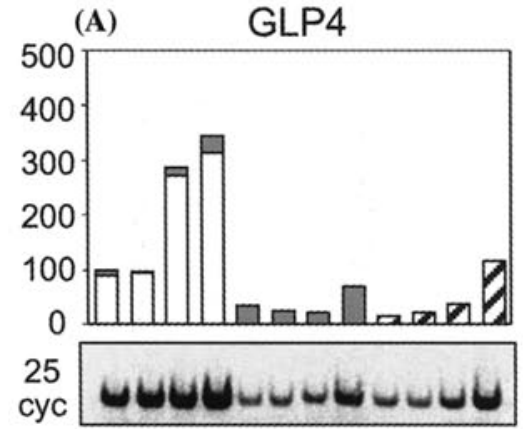

(D) RB_162.7 (ctg 58)
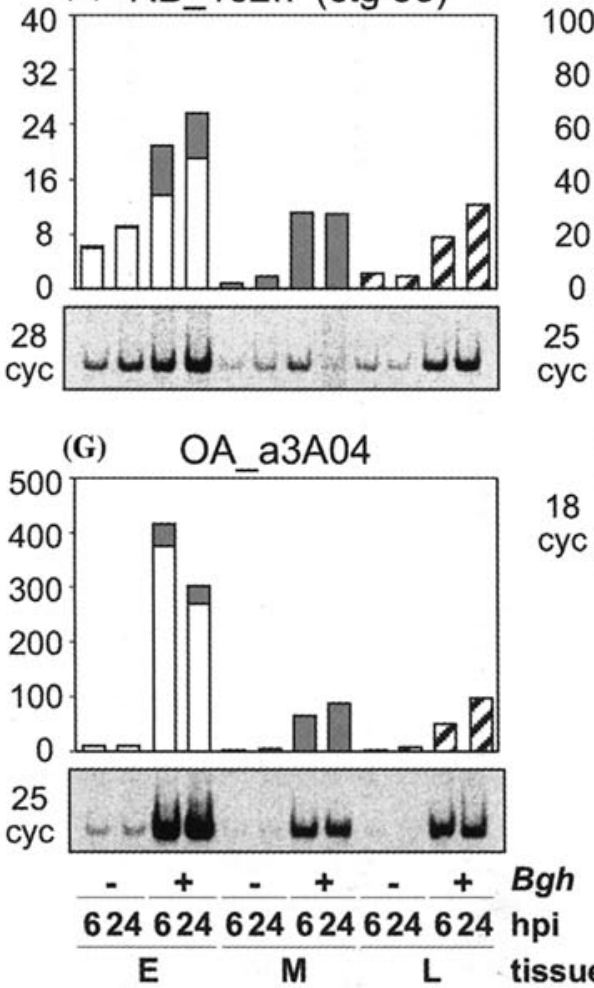

(B) RB_341.7 (ctg 52)

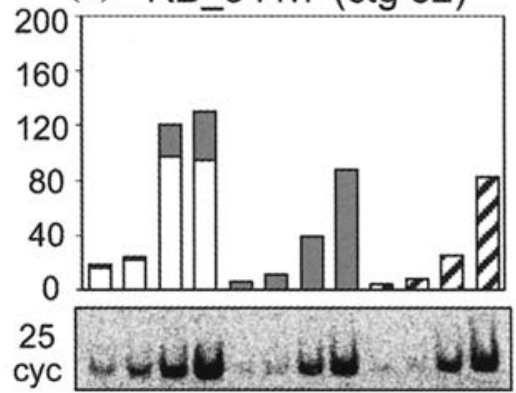

(E) RB $317.3(\operatorname{ctg} 45)$

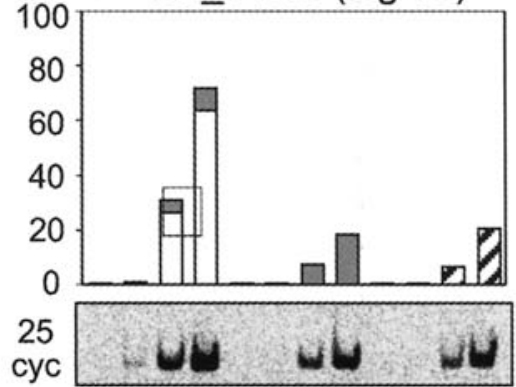

(H)

rubisco

18

cyc

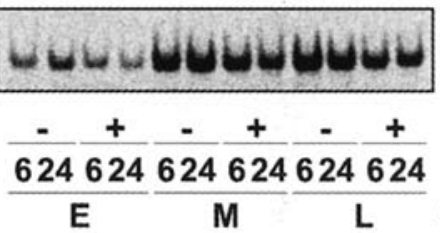

(C) RB_10.1 (ctg 1)

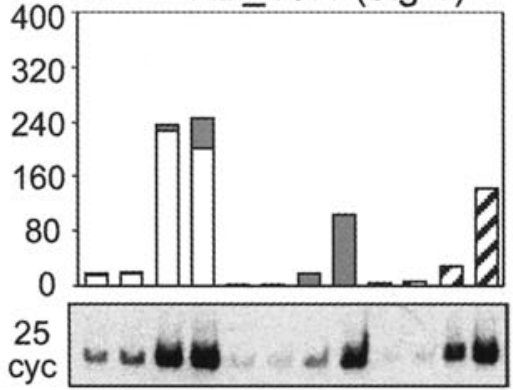

(F) RB_96.3 (ctg 29)

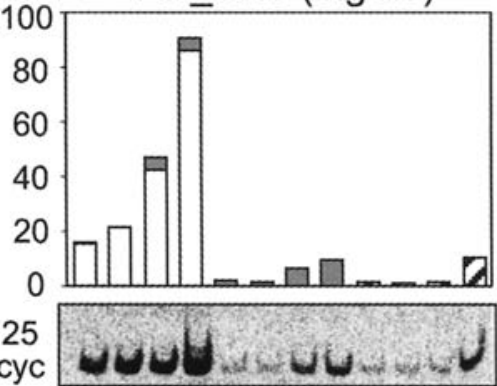

(I) actin

18

cyc

Bgh - + - + - +

hpi 624624624624624624

tissue $\frac{6}{M} \frac{624}{L}$

Figure 2. RT-PCR quantification of selected epidermis-specific transcripts. mRNA levels were determined by RT-PCR using labelled ${ }^{33} \mathrm{P}-\alpha$-dCTP. The relative quantity of amplified DNA was detected using a phosphor imager instrument and was expressed in relative digital light units (DLU). The data were normalised using actin transcripts as a standard. A-G. Average levels in two independent experiments of selected transcripts in Bgh-treated and non-treated wheat tissues (E, epidermis; $M$, mesophyll; $L$, whole leaves) at 6 and $24 \mathrm{hpi}$, respectively. Below each graph, an example of an autoradiogram of a polyacrylamide gel with the reaction products is shown. The PCR cycle (cyc) number is indicated for every sample. An autoradiogram of a polyacrylamide gel with RT-PCR products obtained with rubisco specific primers and actin specific primers is shown in $(\mathrm{H})$ and (I), respectively.

Many different methods exist to normalise data, e.g. total intensity normalisation (Quackenbush, 2002) and LOWESS normalisation (Cleveland, $1979,1981)$. Both methods require as prerequisite that the elements spotted on the array represent a random collection of genes of an organism. The microarrays used in this work, however, represented a selection of genes from screenings. Most of these genes were likely to be induced by $B g h$ and syringolin $A$, respectively, and thus, neither of these normalisation methods or other global methods can be used. Therefore, a normalisation method was developed that relies on a small fraction of genes that likely do not change their expression levels after 
treatment with diverse agents (Reymond et al., 2000). Several putative housekeeping genes and genes which showed no change in expression with several treatments obtained from preliminary experiments were used to calculate a factor that allows the correction of the signal intensities of one channel. Analysis of the normalisation factors of many experiments revealed that the signals of the red channel usually were lower than the signals of the green channel, which confirms the findings of others (Dudoit et al., 2002). Nevertheless, the differences in signal intensities of the control spots between the two channels were relatively small, because the two channels were equalised before acquiring the image with the help of the ScoreCard calibration control spots. Moreover, since the Cy5 signals tended to be weaker than the Cy 3 signals, the induction ratio is likely an underestimation since usually the treatment sample was labelled with Cy5.

Powdery mildew interacts exclusively with the epidermis of the host, and it is therefore of interest to identify the genes which are expressed in epidermis cells. However, epidermis specificity of gene expression difficult to asses when the hybridization probes are derived from epidermis preparations contaminated with an sizable amount of mesoderm tissue, as was the case in our experiments. We tried to correct for the mesophyll contamination by calculating the epidermis specificity value ES from the ratios of test gene signal to rubisco gene signal observed with epidermal and mesophyll probes, respectively. The calculated ES values underestimate the epidermis specificity because the signal of a gene originating from the adaxial epidermis still present in our mesophyll samples attributed to the mesophyll. The epidermal fraction in the mesophyll preparations was estimated by measuring the portion of epidermis and mesophyll areas in cross-sections of primary wheat leaves, which were determined to be approximately $25 \%$ and $75 \%$, respectively (data not shown). Therefore, the remaining adaxial epidermis in mesophyll samples accounted for approximately $12 \%$ of the volume. Moreover, the epidermis consists of different cell types with the majority lacking chloroplasts. However, the guard cells possess chloroplasts and are photosynthetically active. This cell type constitutes about $10-15 \%$ of the number of total cells, and, therefore, contributed in addition to the mesophyll contamination of epidermis samples as estimated from the rubisco gene signal observed with hybridization probes derived from epidermis samples. This may in part also explain that the ES value of several genes was below the value of one, as e.g. thaumatin-like protein (WIR2), which exhibited an ES of 0.5 (Table 2). Another reason for values smaller than one may be that in mesophyll samples, the hybridization of rubisco cDNA with DNA of the rubisco spots reached saturation due to the high concentration of probe representing rubisco transcripts, and, thus, the acquired signal was not proportional to the rubisco cDNA in the hybridization solution. Hence, the rubisco gene expression was likely to be underestimated in experiments with mesophyll probes. In conclusion, on the one hand, overestimation of rubisco expression in epidermis samples and on the other hand, underestimation of rubisco signal in mesophyll samples may have contributed to generally too low ES values. Thus, an ES value of $\geq 2$ as evidence for transcript accumulation in the epidermis certainly is conservative.

\section{Transcripts accumulating in the epidermis upon Bgh-inoculation}

In the cDNA microarray hybridization analysis, transcripts corresponding to many different contigs/clones were shown to exhibit an ES value of $(E S \geq 2)$ and therefore to accumulate in the epidermis after inoculation with $B g h$.

Several genes were identified which likely are involved in detoxification and redox processes. An alternative oxidase transcript (clone OA a1E06, Table 1) showed an exceptionally high ES value of 12. Alternative oxidase (AOX) is a mitochondrial enzyme encoded in the nucleus that may help to reduce reactive oxygen species (ROS) production in mitochondria. $A O X$ antisense tobacco plants show an enhanced hypersensitive response (Vanlerberghe et al., 2002), and, conversely, overexpression protected cells from HR (Maxwell et al., 1999). This may seem paradoxical in the wheat $-B g h$ interaction analysed here, where about $50-70 \%$ of the cells interacting with the fungal spores undergo $H R$ (unpublished observation). Thus, one may speculate that AOX accumulates in mitochondria of cells neighbouring an attacked cell and acts to restrict the size of lesions caused by HR (Ordog et al., 
2002). Two other genes involved in ROS metabolism were induced in the epidermis: GLP4 (AJ237942; Table 1), whose product has recently been shown to exhibit superoxide dismutase activity and to contribute to quantitative powdery mildew resistance in wheat and barley (Schweizer et al., 1999; Christensen et al., 2004), and a peroxidase gene (ctg 114; Table 1). Epidermally induced genes likely involved in detoxification encode a gluthatione- $S$-transferase (OA_b3D05; Table 1), a berberine bridge enzyme-like enzyme, a cytochrome $\mathbf{P} 450$, and mitochondrial NAD-dependent formate dehydrogenase (FDH). In potato, $F D H$ was found to be strongly induced by stresses and by spraying with formate and methanol (Hourton-Cabassa et al., 1998). In plants, a likely source of methanol in leaves is from pectin demethylation of cell walls (Obendorf et al., 1990). An enzyme capable of this reaction is the pectin methyl esterase, which is induced after wounding in Arabidopsis leaves (Reymond et al., 2000). Pectin (e.g. galacturonan) is produced during cell wall synthesis, e.g. cell expansion and pathogen defense (Levy and Staehelin, 1992; Fall and Benson, 1996) and constitutes up to $35 \%$ of the cell wall mass of dicotyledonous plants, but is less abundant in cell walls of grasses. However, the production of methanol may lead to accumulation of formate in epidermal cells, since they produce cell wall components in order to withstand penetration of pathogens. In this regard, the induction of the formate dehydrogenase may be viewed rather as a secondary response to infection than a primary one.

Two epidermally induced genes encode proteins likely involved in vesicle docking. Ctg 99 (Table 1) codes for a protein with similarity to VAP27, a VAP33-like tomato protein found to bind to $C f-9$, the product of the $C f-9$ resistance gene, in a yeast two-hybrid screen (Laurent $e t$ al., 2000). VAP33 was described initially in Aplysia californica as a member of the SNARE complex involved in vesicular docking and neurotransmitter exocytosis (Skehel et al., 1995). VAP33 is a presynaptic membrane protein that interacts specifically with VAMP. This interaction is responsible for the docking and fusion of the synaptic vesicle to the plasma membrane. Thus, transcripts corresponding to ctg 99 encode a protein likely involved in vesicle docking. Clone RB_339.8 (Table 1) encodes a protein with similarity to the Rab family of small G-proteins, members of which are involved in SNARE complex formation during vesicle docking (Südhof, 1997; Sato and Wickner, 1998; Jahn et al., 2003). Vesicle docking has recently been shown to be important in the defense against pathogens in Arabidopsis and barley. The Arabidopsis PENI gene and the barley $R O R 2$ gene, which both are involved in penetration resistance, encode functional syntaxins. Syntaxins are members of the SNARE superfamily that mediate membrane fusion events. Arabidopsis pen I mutant plants exhibit an impaired non-host penetration resistance against barley powdery mildew, whereas the barley $R O R 2$ gene is required for mlo-mediated as well as for basal penetration resistance to $B g h$ (Freialdenhoven et al., 1996). ROR2 interacts with HvSNAP34, a SNAP-25 SNARE homolog in the yeast two-hybrid protein interaction assay and it is required for full resistance (Collins et al., 2003). Since SNARE proteins are required for resistance, it implies a role for membrane fusion in pathogen defense. Indeed, recent observations showed that large vesicles $(2-3 \mu \mathrm{m})$ containing $\mathrm{H}_{2} \mathrm{O}_{2}$ were detected in the host cells beneath appressoria (Collins et al., 2003). Consistently, the accumulation of vesicles at the site of penetration was negatively influenced by ror mutants and the extent of resistance coincided positively with the amount of vesicles.

Several induced genes were identified that encode proteins involved in signal transduction processes. A lectin-like kinase (clone RB_78.2; Table 1) and two leucine-rich repeat (LRR) receptor-like kinases (RLK; ctg 105 and ctg 99.2; Table 1) were specifically expressed in the epidermis. Such proteins may be involved in the recognition of fungus-associated molecular patterns like the one recently described by Schweizer et al. (2000). Recently, Eckey et al. (2004) reported the cloning of a lectin domain-containing receptor-like kinase from powdery mildew-infected barley (accession (AJ427599). The biolistic dsRNAmediated knock-down of the AJ427599-encoded protein resulted in a $26 \%$ reduction of the penetration efficiency of a compatible powdery mildew isolate, suggesting that the corresponding gene was expressed in epidermal cells, because only these cells can be biolistically transformed. However, the protein encoded by RB_78.2 is not closely related in sequence to the AJ427599-encoded protein and thus is not the ortholog. 
One of the most strongly expressed genes in both epidermal and mesophyll tissues was the gene corresponding to $\operatorname{ctg} 1$ (Table 1) which shows similarity to the GIGANTEA (GI) gene. Mutations in the GI gene of Arabidopsis cause a pleiotropic phenotype with effects on flowering time in response to photoperiod, phytochrome $\mathrm{B}$ signalling, the circadian clock and carbohydrate metabolism (Eimert et al., 1995; Fowler et al., 1999; Park et al., 1999; Huq et al., 2000). The GI ortholog of rice was also shown to regulate flowering time in rice (Hayama et al., 2003). Recently, $G I$ was found to be induced 10-fold after cold acclimation in Arabidopsis (Fowler and Thomashow, 2002) and to be localised in the nucleus (Huq et al., 2000). Interestingly, GI was among the proteins found in a yeast two-hybrid screen for proteins that interact with SPINDLY (SPY), and it was shown to interact with the tetratricopeptide repeat (TPR)-domain of SPY. SPY was initially identified as a negative regulator of gibberellin signalling in Arabidopsis, but also functions in previously undefined pathways (Tseng et al., 2004). TPRs can act as scaffolds for the assembly of multiprotein complexes (Blatch and Lassle, 1999), e.g. in the assembly of Hsp70-Hsp90 multichaperone complexes (Scheufler et al., 2000). To our knowledge, no association with responses to pathogen-attack has been reported for $G I$, and the function of this gene with respect to pathogendefense, if any, remains presently unknown.

Genes induced in the mesophyll (ES value $<2$ )

Genes induced by $B g h$ that exhibited an ES value $<2$ and therefore were mostly expressed in the mesophyll are listed in Table 2 . In addition to defenserelated genes encoding homologs of the rice Pir 7 esterases (clone OA_b2A07, OA_b1B01, and ctg 58; Wäspi et al., 1998), superoxide dismutase (ctg 64), and some other proteins, a prominent group of induced genes encode well known PR proteins (Table 2). For the PR-2 ( $\beta$-1,3-glucanases) and PR5 (thaumatin-like proteins; TLPs) classes, several homologous transcripts were found to accumulate following Bgh inoculation.

Three calreticulin transcripts (ctg 44, ctg 14, clone OA_b2C03; Table 2) were also shown to accumulate. Plant calreticulin genes were previously shown to be pathogen-induced and are thought to have a role as chaperones in the endoplasmatic reticulum (ER) necessary for the secretion of PR and other secreted proteins (Denecke et al., 1995; Nelson et al., 1997; JelittoVan Dooren et al., 1999). Apparently, the ER translocation capacity is also increased as transcripts encoding a protein similar to the Sec61 alpha subunit of this translocation apparatus (ctg 121; Table 2) were found to strongly accumulate in response to $B g h$ inoculation. Also induced is a gene encoding a putative UDP-galactose/UDPglucose transporter (ctg 53) which may provide the substrates for protein glycosylation of secreted proteins or polysaccharide biosynthesis in the compartments along the secretory pathways.

Ctg 48 and ctg 27 show similarity to glucosyltransferases. The gene corresponding to ctg 48 was the most strongly induced in the mesophyll (Table 2). The substrates of GTs are quite diverse, including plant hormones, secondary metabolites involved in stress and defense responses, and xenobiotics such as herbicides. These compounds can be activated or inactivated by glucosylation. Glucosides play also a role in the accumulation of phenylpropanoids that would be toxic in their free form and generally, they are stored as glucosides in plants. GTs were identified to be induced after wounding and pathogen-attack (Lee and Raskin, 1999). One of these genes encoding a GT of tomato $(T w i l)$ is involved in the conjugation of small molecular weight substrates such as phenolics and flavonoids (O'Donnell et al., 1998). In tobacco, two GTs, which act on phenylpropanoids and benzoic acid derivates, including salicylic acid, were found to be induced by infection, treatment with elicitors and salicylic acid (Fraissinet-Tachet et al., 1998). Recently, tobacco plants depleted of UDP-Glc:phenylpropanoid glucosyltransferase by antisense expression were shown to be more susceptible to virus infection and to accumulate less scopoletin glucosides (Chong et al., 2002). These results suggest that glucosyltransferases are important in the response to pathogens, however, the substrate of GTs found in this work is presently not known.

Induced genes involved in signal transduction and gene regulation encode a Myb-related transcription factor (clone RB_226.2), a putative histidine kinase (ctg 33), an LRR-RLK (clone RB_286.2), and a protein similar to wall-associated kinases (WAK; ctg 52). The latter proteins contain a cytoplasmatic Ser/Thr kinase (STK) domain and 
an extracellular region with similarity to vertebrate epidermal growth factor (EGF)-like domains. WAKs are considered to physically link the extracellular matrix and the cytoplasm and to be involved in signalling ( $\mathrm{He}$ et al., 1996; Kohorn, 2000; Anderson et al., 2001). Expression of WAK1 in Arabidopsis is stimulated by the resistance activators INA (2,6-dichloroisonicotinic acid) and SA (salicylic acid) as well as by Pseudomonas syringae (He et al., 1998). It has been demonstrated that the induction of $W A K I$ is required for plants to withstand Pseudomonas syringae infection (He et al., 1998). Recently, (Park et al., 2001) demonstrated that a glycine-rich secreted protein of Arabidopsis (AtGRP-3) specifically bound to the extracellular domain of WAK1. Moreover, AtGRP-3 induced $P R-1$ and triggered a positive feedback loop that up-regulated the expression of $W A K 1$ and $A t G R P-3$. In contrast, WAK4 of $A$. thaliana is implicated in cell expansion since silencing of $W A K 4$ resulted in inhibition of cell elongation and an altered morphology (Lally et al., 2001).

In contrast to the epidermis, no induction of subtilisin proteases was detected, but a subtilisinchymotrypsin inhibitor-2-like genes was strongly induced (Table 2).

\section{Induced genes revealed by probes from whole leaves 6 and $24 \mathrm{hpi}$}

As evident from Figure 1, the set of induced genes as revealed by hybridization probes derived from epidermal and mesophyll preparations is not completely congruent with the one obtained with probes from whole leaves. This is probably mainly due to the fact that the latter probe was labelled with a different procedure (indirect labelling) than the former two, which where amplified before the indirect labelling (see Methods). Thus, the distortions in the representation of the true transcript abundances may not have been identical. From the 25 genes uniquely revealed with probes from whole leaves, the two most strongly induced genes seem noteworthy: Clone RB_178.8 corresponds to a protein homologous to a ubiquitin-conjugating enzyme and clone OA_a3C03 to a prohibitin.

Ubiquitin-conjugating enzymes (ubiquitin-carrier proteins) are involved in ubiquitin-proteasome proteolytic pathways the importance of which with respect to plant defense regulation is increasingly recognised (Devoto et al., 2003). Briefly, the target protein is bound to a specific ubiquitin-protein ligase (E3). The ubiquitin-activating enzyme (E1) together with the ubiquitin carrier protein (E2) activate ubiquitin. The activated E2-ubiquitincomplex is bound to a E3-substrate-complex where the ubiquitin is transferred from E2 to the substrate. This step is repeated several times and afterwards, the ubiquitin-tagged substrate is degraded by the $26 \mathrm{~S}$ proteasome complex (Glickman and Ciechanover, 2002). This pathway was shown to regulate hypersensitive cell death mediated by race-specific resistance genes in barley and Arabidopsis, and several genes required for this process encode proteins interacting with $\mathrm{E} 3$ complexes (Austin et al., 2002; Azevedo et al., 2002). Several other E3-ubiquitin-ligases have been identified as candidates for involvement in defense signalling pathways (Salinas-Mondragón et al., 1999; Durrant et al., 2000). However, to date, there are not many reports on ubiquitin-carrier proteins that are up-regulated after fungal treatment, as is the one corresponding to clone RB_178.8.

In barley, the identification of powdery mildewinduced genes by cDNA-AFLP at the 4 and $12 \mathrm{hpi}$ timepoints has recently been reported (Eckey et al., 2004). In these experiments, whole leave material was used. For 29 ESTs, $B g h$-induced transcript accumulation was shown using RT-PCR. In addition to the lectin domain-containing receptor like kinase mentioned above, a number of proteins are encoded by these clones that are similar to peptides encoded by clones identified in this study: A putative peptide transporter (AJ495773/ctg 21; Table 2), phenylalanin ammonia-lyase (AJ427587 and BE415189/ctg 101 and ctg 11; Tables 1 and 3, respectively), a cytochrome P450 (AJ495774/ctg 36; Table 3), and a 3-phosphoshikimate 1-carboxyvinyltransferase (AJ495777/ctg 119; Table 2). Differences in the nature of CDNA-AFLP clones obtained in our work and the one of Eckey et al. (2004) may be due to a number of causes, including different experimental setup (epidermis preparation vs. whole leaf tissue), different time points, and the use of different plant species.

Contig 119 (Table 2) encodes a putative 3-phosphoshikimate 1-carboxyvinyltransferase, an enzyme involved in chorismate synthesis. Transcripts encoding several enzymes in the shikimate pathway were also shown to be members of 
a set of 22 transcripts accumulating both in compatible and incompatible interactions of powdery mildew with barley until about $16 \mathrm{hpi}$, but afterwards differing in abundance: in compatible interaction this set decreases in abundance, while in incompatible interactions, a high abundance is maintained for a longer time (Caldo et al., 2004). This pattern suggested that in compatible interactions, the fungus is able to suppress host defense responses. We have previously found evidence for suppression of expression of certain wheat PR protein genes in compatible powdery mildew/ wheat interactions (Wäspi et al., 2001). Although other transcripts in the set of 22 transcripts encode proteins in pathways (e.g. oxidative stress, lignin biosynthesis) to which also proteins belong encoded by clones found in this work, we cannot draw any conclusions about their time course behaviour with regard to compatible or incompatible interactions.

In conclusion, hybridization of microarrays of cloned cDNA-AFLP fragments using probes derived from epidermal and mesophyll tissue preparations of wheat leaves has allowed to determine the tissue specific expression of a set of genes that are activated upon Bgh inoculation. Overexpression (after cloning of full length cDNAs) and suppression by RNA interference of genes induced in the epidermis using the transient ballistic expression system previously described (Schachermayr et al., 1994; Schweizer et al., 1999, 2000) will allow the functional characterization of this set of genes in resistance against wheat powdery mildew.

\section{Material and methods}

\section{Plant and fungal growth conditions and treatment}

Plants were grown on standard soil (Einheitserde, Buchenberg, Germany) in a growth chamber ( $16 \mathrm{~h}$ light period at $22,8 \mathrm{~h}$ dark period at $18{ }^{\circ} \mathrm{C} ; 60 \%$ relative humidity).

The powdery mildew fungi Blumeria graminis $\mathrm{f}$. sp. hordei (Bgh, Reckenholz accession (4.8) and Blumeria graminis f. sp. tritici (Bgt, Reckenholz accession (92315), both Swiss field isolates, were maintained on Hordeum vulgare cv. Express and Triticum aestivum cv. Arina, respectively, by weekly transfer to fresh plants.
Inoculation of wheat plants with powdery mildew fungi was usually made with 7-day-oldseedlings at a spore density of 150-250 conidia/ $\mathrm{mm}^{2}$. Wheat plants were inoculated with either the incompatible fungus $(B g h)$ or the compatible fungus $(B g t)$ by brushing barley or wheat plants infected one week earlier over the test plants. Plant material was collected from different tissues at various time points after infection.

For the cDNA-AFLP screening, wheat seedlings (Triticum aestivum cv. Fidel, winter wheat) were grown in 20 pots, each containing $10-12$ seedlings, in the same growth chamber. The plants of 10 randomly chosen pots were mockinoculated, while the remaining plants were treated with Blumeria graminis f. sp. hordei (Reckenholz accession (92315) at a spore density of 200 conidia $/ \mathrm{mm}^{2}$. This interaction is completely incompatible. About $50-70 \%$ of the wheat epidermal cells attacked by this fungal isolate undergo hypersensitive cell death, whereas the remaining cells prevent penetration by the fungus through papilla formation. Inoculated and un-inoculated control plants were then again incubated in the same growth cabinet. The abaxial epidermis of $B g h$-treated and non-treated first leaves of all plants was harvested after 6-9 and 23-26 hpi, respectively, and immediately frozen in liquid nitrogen. The same experimental setup was also used for the preparation of microarray hybridization probes, except that in addition to the abaxial epidermis, the remainder of the stripped leaves was also collected, and for some experiments whole first leaves where harvested.

\section{$R N A$ extraction and poly $(A)^{+} R N A$ isolation}

RNA was isolated from collected plant material that was ground to a fine powder in liquid nitrogen using pestle and mortar. The material was suspended in a 1:1 mixture of phenol and $2 \times$ NETS ( $200 \mathrm{mM} \mathrm{NaCl}, 2 \mathrm{mM}$ EDTA, $20 \mathrm{mM}$ Tris- $\mathrm{HCl}$, $1 \%$ SDS, pH 7.5) that was preheated to $80^{\circ} \mathrm{C}$ (Dudler and Hertig, 1992).

Poly $(\mathrm{A})^{+}$RNA was isolated from 200 to $1000 \mu \mathrm{g}$ of total RNA using oligo(dT) OLIGOTEX $^{\circledR}$ (Qiagen, Basel, Switzerland). All steps were performed according to manufacturer's protocol. 
Template preparation, amplified fragment length polymorphism ( $A F L P$ ) and PAGE analysis

The cDNA used for cDNA-AFLP was synthesised using a cDNA-synthesis kit of Invitrogen (Invitrogen, Basel, Switzerland; Cat. No. 18267-013) according to manufacturer's protocol. Starting material for each reaction was $2 \mu \mathrm{g}$ of $\operatorname{poly}(\mathrm{A})^{+}$ RNA derived from epidermal RNA. The template for cDNA-AFLP was prepared according to Vos et al. (1995) and Bachem et al. (1996). The cDNA was digested with the restriction enzymes $N c o I$ and Sau3AI (Amersham Biosciences, Uppsala, Sweden). Next, $N c o$ I and Sau3AI adapters were ligated to the cDNA fragments using T4 DNA ligase (Roche Applied Science, Penzberg, Germany). Following ligation, cDNA fragments were subjected to PCR pre-amplification. The 20 times diluted pre-amplification product was as a template in the selective PCR amplification reaction.

The sequences of adapters and primers used for cDNA-AFLP and the PCR reaction conditions were as follows: $N c o$ I adapter top strand, 5'-CCTGTAGACTGCGTACAC-3'; NcoI adapter bottom strand: 5'-CATGGTGTACGCAGTCTA C-3'; Sau3AI adapter top strand, 5'-AGCGATGAGTCCTGAG3'; Sau3AI adapter bottom strand, 5'-GATCCTCAGGACTCAT-3'; NcoI preamplification primer, 5'-AGACTGCGTACACCATGG-3'; Sau3AI preamplification primer, 5'-ATGAGTCCTGAGGATC-3'; NcoI selective amplification primers, 5'AGACTGCGTACACCATGGNN-3'; Sau3AI selective amplification primers, 5'-ATGA GTCCTGAGGATCNN-3'. All oligonucleotides were HPLC purified (Microsynth AG, Balgach, Switzerland). The NcoI and Sau3AI bottom strand oligonucleotides were phosphorylated at the $5^{\prime}$ end using T4 polynucleotide kinase (Amersham Biosciences, Uppsala, Sweden), annealed to the corresponding primer and ligated to the digested cDNA. Preamplification reactions were performed with an initial 2 min synthesis step at $72{ }^{\circ} \mathrm{C}$ following 20 cycles $\left(30 \mathrm{~s}, 94^{\circ} \mathrm{C} ; 60 \mathrm{~s}, 60^{\circ} \mathrm{C} ; 2 \mathrm{~min}, 72^{\circ} \mathrm{C}\right)$ and a final elongation step $\left(2 \mathrm{~min}, 72^{\circ} \mathrm{C}\right)$. The product was diluted 20 times (total volume: $400 \mu \mathrm{l}$ ). The selective $\mathrm{N}$-primers were labelled with $\left[\gamma_{-}{ }^{33} \mathrm{P}\right]$-ATP at the 5 '-end using T4 polynucleotide kinase. Each primer labelling reaction was performed in a $25 \mu \mathrm{l}$ volume containing $10 \mu \mathrm{M} \quad \mathrm{N}$-primer, $50 \mu \mathrm{Ci}$ $\left[\gamma^{33} \mathrm{P}\right]-\mathrm{ATP}$ (Hartmann Analytic GmbH, Glattbrugg, Switzerland), $1 \times$ reaction buffer $(10 \mathrm{mM}$
Tris-acetate, $50 \mathrm{mM} \mathrm{K}$-acetate, $\mathrm{pH}$ 7.5), and $0.5 \mathrm{U}$ polynucleotide kinase (Amersham Biosciences, Uppsala, Sweden). A touch down thermocycling reaction was carried out in a $20 \mu \mathrm{l}$ volume containing $3 \mu \mathrm{l}$ template from the pre-amplification step, $0.3 \mu \mathrm{M}$ labelled $\mathrm{N}$-primer, $0.3 \mu \mathrm{M}$ S-primer, $200 \mu \mathrm{M}$ each for dATP, dGTP, dCTP and dTTP, $1 \times$ reaction buffer $(10 \mathrm{mM}$ Tris- $\mathrm{HCl} \mathrm{pH} 9,1.5 \mathrm{mM}$ $\mathrm{MgCl}_{2}, 50 \mathrm{mM} \mathrm{KCl}$, Amersham Biosciences) and 1 unit Taq-polymerase (Amersham Biosciences) using the settings: $2 \mathrm{~min}, 94^{\circ} \mathrm{C}\left[30 \mathrm{~s}, 94^{\circ} \mathrm{C} ; 30 \mathrm{~s}\right.$, $65-0.9^{\circ} \mathrm{C}$ per cycle; $\left.2 \mathrm{~min}, 72^{\circ} \mathrm{C}\right] 9$ cycles $[30 \mathrm{~s}$, $\left.94^{\circ} \mathrm{C} ; 30 \mathrm{~s}, 57^{\circ} \mathrm{C} ; 2 \mathrm{~min}, 72^{\circ} \mathrm{C}\right] 23$ cycles. All amplification reactions were performed in a $\mathrm{PE}$ GeneAmp 9600 thermocycler (Perkin-Elmer Life and Analytical Sciences, Monza, Italy)

Selective amplification products were mixed with formamide dye $(98 \%$ formamide, $10 \mathrm{mM}$ EDTA pH 8, bromophenol blue, xylenecyanol) at a 2:1 ratio and $3 \mu \mathrm{l}$ of each product was separated on a polyacrylamide gel ( $5 \%$ acrylamide, $0.25 \%$ bisacrylamide, $7.5 \mathrm{M}$ urea, $1 \times$ TBE $[89 \mathrm{mM}$ Trisborate, $2 \mathrm{mM}$ EDTA, $\mathrm{pH} 8])$. The electrophoresis was performed at $52{ }^{\circ} \mathrm{C}(\sim 100 \mathrm{~W})$ until the bromophenol blue reached the bottom of the gel. Gels were dried onto Whatman 3MM paper (Whatman, Maidstone, UK), positionally marked with a stapler on Kodak Biomax MR film (Kodak, New Haven, USA, CAT 871 5187) and exposed for $1.5 \mathrm{~d}$ at room temperature.

\section{Isolation, subcloning and sequencing of AFLP fragments}

The developed films were aligned on the gels with staples. The bands of interest were excised from the dried gel with a scalpel and incubated for $1 \mathrm{~h}$ at 37 on a benchtop shaker (Vaudaux-Eppendorf AG, Schönenbuch, Switzerland) in $100 \mu \mathrm{TE}(10 \mathrm{mM}$ Tris, $1 \mathrm{mM}$ EDTA, $\mathrm{pH} 8)$ and stored at $-20^{\circ} \mathrm{C}$. Excision of the correct band was controlled by exposing the gel again to an X-ray film. The fragments were recovered by PCR using the preamplification conditions (no initial 2 min synthesis step) and performing 30 cycles. PCR products were purified with GFX spin columns (Amersham Biosciences, Uppsala, Sweden), digested with NcoI/Sau3AI (Amersham Biosciences, Uppsala, Sweden) and ligated to a modified cloning vector pBSK + (Stratagene, La Jolla, USA) containing an $N c o$ I site between the PstI and SmaI sites in the 
multiple cloning site. To achieve this, the oligonucleotides 5'-GCCATGGCCCGGGG and 5'. GATCCCCCGGGCCATGGCTGCA were annealed and ligated between the Pst I and BamHI sites of the multiple cloning site.

Sequences were determined using an automated sequencer (ABI377, Applied Biosystems, Foster City, USA) and were compared to DNA and protein sequence databases (including the wheat, barley, and rice EST databases with 595000 , 393000 , and 370000 entries as of December 2004) with the programs blastn, blastx tblastx (Altschul et al., 1990).

\section{Microarray preparation}

Inserts of cDNA-AFLP clones were amplified by polymerase chain reaction (PCR) using M13 reverse and M13 forward primers carrying an amino group at the $5^{\prime}$-hydroxy end. All steps were carried out according to Reymond et al. (2000) except that the spotting solution was $3 \times \mathrm{SSC}, 3 \mathrm{M}$ betaine.

Microarray fabrication was performed according to published methods (Schena et al., 1995; Shalon et al., 1996, Reymond, 2000 (1166) using an OmniGrid 100 gridding robot equipped with 8 printing pins (Genomic Solutions, Ann Harbor, USA).

\section{Preparation of fluorescent probes}

For microarray hybridization experiments, fluorescent probes were prepared from RNA extracted from inoculated and uninoculated wheat plants.

Indirect labelling: Purified polyA + RNA was reverse transcribed in the presence of aminoallyldUTP. Two $\mu \mathrm{g}$ polyA + RNA was mixed with $2 \mu \mathrm{l}$ primer-mix $(500 \mathrm{ng} / \mu \mathrm{l}$ oligo-dT (21-mer), $600 \mathrm{ng} / \mu \mathrm{l}$ random nonamer and, optionally, with $2 \mu$ l Lucidea ScoreCard Spike RNA [Amersham Biosciences, Uppsala, Sweden]). The volume of the sample was adjusted to $15 \mu$ with $\mathrm{H}_{2} \mathrm{O}$ and incubated at $70^{\circ} \mathrm{C}$ for $10 \mathrm{~min}$. After the sample was cooled on ice for $5 \mathrm{~min}$, the following components were added: $5 \mu \mathrm{l} 5 \times$ first-strandbuffer (Invitrogen AG, Basel, Switzerland), 50x aminoallyl-dNTP mix (25 mM dGTP, $25 \mathrm{mM}$ dCTP, $25 \mathrm{mM}$ dATP, $17.5 \mathrm{mM}$ aa-dUTP, $7.5 \mathrm{mM}$ dUTP, Sigma-Aldrich, Buchs SG,
Switzerland), $2.5 \mu \mathrm{l}$ DTT $0.1 \mathrm{mM}$ (Invitrogen), $0.7 \mu \mathrm{l}$ RNaseOUT (40 U/ $\mu \mathrm{l}$ Invitrogen), $0.3 \mu \mathrm{l}$ $\mathrm{H}_{2} \mathrm{O}$ (RNase free) and $1 \mu \mathrm{l}$ SuperScript II reverse transcriptase (200 $\mathrm{U} / \mu 1$, Invitrogen). The sample was put at $25^{\circ} \mathrm{C}$ for $10 \mathrm{~min}$, then incubated for $2 \mathrm{~h}$ at $42^{\circ} \mathrm{C}$. After $1 \mathrm{~h}$ at $42^{\circ} \mathrm{C}$, additional $(1 \mu \mathrm{l})$ SuperScript II was added. To inactivate the enzyme, the samples were incubated at $70^{\circ} \mathrm{C}$ for $10 \mathrm{~min}$. Afterwards, $0.5 \mu \mathrm{l}$ RNase $\mathrm{H}(5 \mathrm{U} / \mu \mathrm{l}$, Amersham Biosciences) was added and samples were incubated for $15 \mathrm{~min}$ at $37^{\circ} \mathrm{C}$. To purify the sample, $0.5 \mu \mathrm{l}$ EDTA (pH 8) and $2.5 \mu \mathrm{l}$ QuickClean resin (BD Biosciences, Basel, Switzerland) was added, vortexed for $1 \mathrm{~min}$ and briefly centrifuged. The supernatant was applied onto a $0.45 \mu \mathrm{m}$ spin filter (Cat. No. UFC3 OHV 25, Millipore, Volketswil, Switzerland) and centrifuged for $2 \mathrm{~min}$ at $12000 \times \mathrm{g}$. The nucleic acids were precipitated by adding $150 \mu \mathrm{l}$ TouchDown precipitation reagent according to the manufacturer's protocol (ActiveMotiv, Rixensart, Belgium). The dried pellet was dissolved in $10 \mu \mathrm{l}$ $1.5 \times$ coupling buffer $(75 \mathrm{mM}$ sodium bicarbonate, $\mathrm{pH}$ 9). Afterwards, $5 \mu \mathrm{l}$ of fluorescent dye (7.5 mM; Cy3 or Cy5, Amersham Biosciences; AlexaFluor 555 or AlexaFluor647, Molecular Probes, Leiden, The Netherlands) dissolved in DMSO (BD Biosciences) was added to the sample and incubated for $1 \mathrm{~h}$ at room temperature in the dark. The labelled DNA was precipitated with $75 \mu \mathrm{l}$ TouchDown precipitation reagent and the pellet was dissolved in $100 \mu \mathrm{l}$ $\mathrm{dH}_{2} \mathrm{O}$. The probe was purified using the Qiaquick PCR Purification Kit (Qiagen, Basel, Switzerland). The steps were carried out according to manufacturer's protocol except that three washing steps were performed instead of one and that the DNA was eluted twice with $35 \mu 1$ Tris-Cl $(2.5 \mathrm{mM}, \mathrm{pH} 8)$ at $50^{\circ} \mathrm{C}$. For each probe, a photospectrum was taken to ensure frequencies of incorporated dye per 1000 nucleotides of 15 or more. The two differently labelled probes (control and treated sample) were pooled and dried to completion. The pellet was dissolved with $60 \mu \mathrm{l}$ hybridisation buffer $(0.4 \%$ SDS, $3 \times \mathrm{SSC}, 4 \mathrm{ng} / \mu \mathrm{l}$ tRNA.

Amplification labelling: Samples with limited starting material were labelled using an amplification step. cDNA synthesis was carried out with $1 \mu \mathrm{g}$ total RNA and T7-oligo(dT) primer (MessageAmp aRNA-Kit; Ambion, Cambridgeshire, 
UK). Subsequently, cDNA was in vitro transcribed using T7 RNA polymerase producing antisense RNA (aRNA). The amplified aRNA was used as template for the indirect labelling procedure described above. The only difference was that oligo(dT) primers were omitted and more random nonamers $(2 \mu \mathrm{g})$ were used. rial, table) to determine the correction factor $F$. The factor was calculated as the median of the sum of the quotient of the net values of both channels. The formula is shown below:

The background signal was determined by the mean signal of the ScoreCard negative control spots and used as cut-off value. Spots with signals

$$
F=\text { median }_{x \in \text { housekeeping spots }}\left(\frac{(\text { cy5 signal mean }) x-(c y 5 \text { back ground median }) x}{(\text { cy3 signal mean }) x-(c y 3 \text { back ground median }) x}\right)
$$

\section{Hybridization reaction, scanning and microarray analysis}

Before hybridisation, the probe solution was boiled for $2 \mathrm{~min}$, centrifuged for $1 \mathrm{~min}$ at $12000 \times g$ and then rapidly applied to the microarray under a cover slip having two protruding edges (Lifterslips, Erie Scientific Company, Portsmouth, USA). The assembly was placed into a hybridisation chamber (TeleChem International Inc., Sunnyvale, USA). Before the chambers were sealed, $100 \mu \mathrm{l}$ hybridisation buffer was put into the two grooves on each side of the chamber. The slides were incubated $14-16 \mathrm{~h}$ in a water bath at $64{ }^{\circ} \mathrm{C}$ in a dark place and subsequently washed in the following solutions: $2 \times$ SSC, $0.1 \%$ SDS twice for $5 \mathrm{~min}, 0.2 \times \mathrm{SSC}$ twice for $1 \mathrm{~min}, 0.1 \times \mathrm{SSC}$ twice for $1 \mathrm{~min}$. Slides were dried by centrifugation at $130 \times g$ for $5 \mathrm{~min}$ before scanning.

Microarrays were scanned with a scanning laser microscope (ScanArray 5000; PerkinElmer Life and Analytical Sciences, Monza, Italy). Separate images were acquired for each fluor at a resolution of $10 \mu \mathrm{m}$ per pixel. To normalise the two channels with respect to signal intensity, the photomultiplier and the laser power settings were adjusted such that the signal ratio of the ScoreCard calibration controls was as close to 1.0 as possible.

The average fluorescence intensity for each fluor and for each gene was determined by using ImaGene 4.2 software (Biodiscovery Inc., El Segundo, USA). The parameters of data acquisition were the following: signal low, 0 ; signal high, 1; background low, 0.03; background high, 0.95; background buffer, 4; background width, 20 .

To correct for variations in samples of control and treatment, the data were normalised using putative housekeeping genes (supplementary mate- lower than the cut-off value were set to this value.

The expression ratios were determined using the normalised signal intensities. To identify differentially expressed genes, a Student's $t$ test was performed on $\log _{2}$-transformed expression ratios to check whether the ratios were different from 1 (one sample hypothesis). If a gene was represented by more than one spot on the microarray, the ratios of all spots were included in the analysis. For all experiments, only genes with an expression ratio $\geq 2$ and a $P$ value $<0.05$ were considered.

\section{$R T-P C R$ analysis}

Total RNA was treated with DNase (Qiagen, Basel, Switzerland) and cleaned up with RNeasy columns (Qiagen, Basel, Switzerland) according to the manufacturer's protocol. Each first strand cDNA reaction was performed in a $20 \mu 1$ volume containing $1 \mu \mathrm{g}$ of total RNA, $0.5 \mu \mathrm{g}$ oligo(dT) 21-mer, $500 \mu \mathrm{M}$ each for dATP, dGTP, dCTP and dTTP, 40 units of RNase inhibitor (RNaseOUT, Invitrogen AG, Basel, Switzerland), $10 \mathrm{mM}$ DTT (Invitrogen), $1 \times$ reaction buffer (50 mM Tris- $\mathrm{HCl}$, pH $8.3 ; 75 \mathrm{mM} \mathrm{KCl} ; 3 \mathrm{mM}$ $\mathrm{MgCl}_{2}$ ) and 200 units Superscript II (Invitrogen). After incubation at $42^{\circ} \mathrm{C}$ for $1 \mathrm{~h}$, the reaction was stopped by incubation at $70{ }^{\circ} \mathrm{C}$ for $15 \mathrm{~min}$.

PCR was carried out in a $25 \mu \mathrm{l}$ volume containing $1.6 \mu \mathrm{l}$ of the first strand product, $200 \mu \mathrm{M}$ of each dATP, dGTP, dCTP and dTTP, $300 \mathrm{nM}$ of each primer, $2 \mu \mathrm{Ci}\left[\alpha-{ }^{33} \mathrm{P}\right]-\mathrm{dCTP}$ (Hartmann Analytic $\mathrm{GmbH}$, Glattbrugg, Switzerland), 1× reaction buffer $(10 \mathrm{mM}$ Tris- $\mathrm{HCl}, \mathrm{pH} 8.3$, $50 \mathrm{mM} \mathrm{KCl}, 1.5 \mathrm{mM} \mathrm{MgCl} 2$ and $0.001 \%$ gelatine) 1 unit Taq-polymerase (Sigma-Aldrich, Buchs SG, Switzerland). The thermocycling conditions were: 
$94{ }^{\circ} \mathrm{C}, 2 \mathrm{~min}\left[94^{\circ} \mathrm{C}, 15 \mathrm{~min} ; 60^{\circ} \mathrm{C}, 60 \mathrm{~min}\right] \times 19$ 31 cycles. Aliquots of $5 \mu \mathrm{l}$ were taken every 3 cycles starting at 19 cycles. The reactions were carried out in a T-Gradient cycler (Biometra, Châtel-St-Denis, Switzerland).

Products $(5 \mu \mathrm{l})$ were mixed with $1 \mu \mathrm{l}$ of gel loading buffer $(30 \%$ glycerol, $1 \times$ TBE, $0.25 \%$ bromophenol blue, $0.25 \%$ Orange G) and separated on a non-denaturing polyacrylamide gel $(5 \%$ acrylamide, $0.25 \%$ bisacrylamide, $1 \times$ TBE). The electrophoresis was performed at $50 \mathrm{~V}$ until the Orange $\mathrm{G}$ reached the bottom of the gel. Gels were dried onto Whatman 3MM paper, exposed to a phosphor screen (Perkin-Elmer Life and Analytical Sciences, Monza, Italy) for 30-60 min and scanned with a Cyclone-Storage-Phosphor-System (Perkin-Elmer). The quantification of the gel bands was carried out using OptiQuant software (PerkinElmer).

\section{Acknowledgements}

The authors thank E.E. Farmer, University of Lausanne, for use of the Gene Expression Laboratory Microarray facility at the Department of Plant Molecular Biology, and Thomas Wicker for help with bioinformatics tasks. Support by the Swiss National Science Foundation (grants 3100A0-100046 and 3100-058656 to R.D.), the Functional Genomics Center Zurich, and the Kanton Zürich is acknowledged.

\section{References}

Alexander, D., Goodman, R.M., Gut-Rella, M., Glascock, D., Weymann, K., Friedrich, L., Maddox, D., Ahl-Goy, P., Luntz, T., Ward, E. and Ryals, J. 1993. Increased tolerance to two oomycete pathogens in transgenic tobacco expressing pathogenesis-related protein la. Proc. Natl. Acad. Sci. USA 90: 7327-7331.

Altpeter, F., Varshney, A., Abderhalden, O., Douchkov, D., Sautter, C., Kumlehn, J., Dudler, R. and Schweizer, P. 2005. Stable expression of a defense-related gene in wheat epidermis under transcriptional control of a novel promoter confers pathogen resistance. Plant Mol. Biol. in press.

Altschul, S.F., Gish, W., Miller, W., Myers, E.W. and Lipman, D.J 1990. Basic local alignment search tool. J. Mol. Biol. 215: 403-410.

Anderson, C.M., Wagner, T.A., Perret, M., He, Z.H., He, D.Z. and Kohorn, B.D. 2001. WAKs: cell wall-associated kinases linking the cytoplasm to the extracellular matrix. Plant Mol. Biol. 47: 197-206.

Austin, M.J., Muskett, P., Kahn, K., Feys, B.J., Jones, J.D.G. and Parker, J.E. 2002. Regulatory role of SGT1 in early $R$ gene-mediated plant defenses. Science 295: 2077-2080.

Azevedo, C., Sadanandom, A., Kitagawa, K., Freialdenhoven, A., Shirasu, K. and Schulze-Lefert, P. 2002. The RAR1 interactor SGT1, an essential component of $R$ gene-triggered disease resistance. Science 295: 2073-2076.

Bachem, C.W., van der Hoeven, R.S., de Bruijn, S.M., Vreugdenhil, D., Zabeau, M. and Visser, R.G. 1996. Visualization of differential gene expression using a novel method of RNA fingerprinting based on AFLP: analysis of gene expression during potato tuber development. Plant $\mathbf{J}$. 9: $745-753$

Blatch, G.L. and Lassle, M. 1999. The tetratricopeptide repeat: a structural motif mediating protein protein interactions. Bioessays 21: 932-939.

Broglie, K., Chet, I., Holliday, M., Cressman, R., Biddle, P., Knowlton, S., Mauvais, C.J. and Broglie, R. 1991. Transgenic plants with enhanced resistance to the fungal pathogen Rhizoctonia solani. Science 254: 1194-1197.

Caldo, R.A., Nettleton, D. and Wise, R.P. 2004. Interactiondependent gene expression in Mla-specified response to barley powdery mildew. Plant Cell 16: 2514-2528.

Chong, J., Baltz, R., Schmitt, C., Beffa, R., Fritig, B. and Saindrenan, P. 2002. Downregulation of a pathogen-responsive tobacco UDP-Glc: phenylpropanoid glucosyltransferase reduces scopoletin glucoside accumulation, enhances oxidative stress, and weakens virus resistance. Plant Cell 14: 10931107.

Christensen, A.B., Thordal-Christensen, H., Zimmermann, G., Gjetting, T., Lyngkjaer, M.F., Dudler, R. and Schweizer, P. 2004. The germinlike protein GLP4 exhibits superoxide dismutase activity and is an important component of quantitative resistance in wheat and barley. Mol. PlantMicrobe Interact. 17: 109-117.

Cleveland, W.S 1979. Robust locally weighted regression and smoothing scatterplots. J. Am. Stat. Assoc. 74: 829-836.

Cleveland, W.S. 1981. Lowess - a program for smoothing scatterplots by robust locally weighted regression. Am. Stat. 35: $54-54$

Collins, N.C., Thordal-Christensen, H., Lipka, V., Bau, S., Kombrink, E., Qiu, J.L., Huckelhoven, R., Stein, M., Freialdenhoven, A., Somerville, S.C. and Schulze-Lefert, P. 2003. SNARE-protein-mediated disease resistance at the plant cell wall. Nature 425: 973-977.

Denecke, J., Carlsson, L.E., Vidal, S., Hoglund, A.S., Ek, B. van Zeijl, M.J., Sinjorgo, K. and Palva, E.T. 1995. The tobacco homolog of mammalian calreticulin is present in protein complexes in vivo. Plant Cell 7: 391-406.

Devoto, A., Muskett, P.R. and Shirasu, K. 2003. Role of ubiquitination in the regulation of plant defence against pathogens. Curr. Opin. Plant Biol. 6: 307-311.

Diatchenko, L., Lau, Y.F.C., Campbell, A.P., Chenchik, A., Moqadam, F., Huang, B., Lukyanov, S., Lukyanov, K., Gurskaya, N., Sverdlov, E.D. and Siebert, P.D. 1996. Suppression subtractive hybridization: a method for generating differentially regulated or tissue-specific cDNA probes and libraries. Proc. Natl. Acad. Sci USA 93: 6025 6030.

Dudler, R. and Hertig, C. 1992. Structure of an mdr-like gene from Arabidopsis thaliana: evolutionary implications. J. Biol. Chem. 267: 5882-5888. 
Dudoit, S., Yang, Y.H., Callow, M.J. and Speed, T.P 2002. Statistical methods for identifying differentially expressed genes in replicated cDNA microarray experiments. Stat. Sin. 12: 111-139.

Durrant, W.E. and Dong, X. 2004. Systemic acquired resistance. Annu. Rev. Phytopathol. 42: 185-209.

Durrant, W.E., Rowland, O., Piedras, P., Hammond-Kosack, K.E. and Jones, J.D.G. 2000. cDNA-AFLP reveals a striking overlap in race-specific resistance and wound response gene expression profiles. Plant Cell 12: 963-977.

Eckey, C., Korell, M., Leib, K., Biedenkopf, D., Jansen, C., Langen, G. and Kogel, K.-H. 2004. Identification of powdery mildew-induced barley genes by cDNA-AFLP: functional assessment of an early expressed MAP kinase. Plant Mol. Biol. 55: 1-15.

Eimert, K., Wang, S.M., Lue, W.L. and Chen, J.C. 1995. Monogenic recessive mutations causing both late floral initiation and excess starch accumulation in Arabidopsis. Plant Cell 7: 1703-1712.

Eisen, M.B. and Brown, P.O. 1999. DNA arrays for analysis of gene expression. Meth. Enzymol. 303: 179-205.

Fall, R. and Benson, A.A. 1996. Leaf methanol - the simplest natural product from plants. Trends Plant Sci. 1: 296-301.

Fowler, S. and Thomashow, M.F. 2002. Arabidopsis transcriptome profiling indicates that multiple regulatory pathways are activated during cold acclimation in addition to the $\mathrm{CBF}$ cold response pathway. Plant Cell 14: 1675-1690.

Fowler, S., Lee, K., Onouchi, H., Samach, A., Richardson, K., Coupland, G. and Putterill, J. 1999. GIGANTEA: a circadian clock-controlled gene that regulates photoperiodic flowering in Arabidopsis and encodes a protein with several possible membrane-spanning domains. Embo J. 18: 4679-4688.

Fraissinet-Tachet, L., Baltz, R., Chong, J., Kauffmann, S., Fritig, B. and Saindrenan, P. 1998. Two tobacco genes induced by infection, elicitor and salicylic acid encode glucosyltransferases acting on phenylpropanoids and benzoic acid derivatives, including salicylic acid. FEBS Lett. 437: 319-323.

Freialdenhoven, A., Peterhänsel, C., Kurth, J., Kreuzaler, F. and Schulze-Lefert, P. 1996. Identification of genes required for the function of non-race-specific mlo resistance to powdery mildew in barley. Plant Cell 8: 5-14.

Glickman, M.H. and Ciechanover, A. 2002. The ubiquitinproteasome proteolytic pathway: destruction for the sake of construction. Physiol. Rev. 82: 373-428.

Görlach, J., Volrath, S., Knauf Beiter, G., Hengy, G., Beckhove, U., Kogel, K.H., Oostendorp, M., Staub, T., Ward, E., Kessmann, H. and Ryals, J. 1996. Benzothiadiazole, a novel class of inducers of systemic acquired resistance, activates gene expression and disease resistance in wheat. Plant Cell 8: 629-643.

Grison, R., GrezesBesset, B., Schneider, M., Lucante, N., Olsen, L., Leguay, J.J. and Toppan, A. 1996. Field tolerance to fungal pathogens of Brassica napus constitutively expressing a chimeric chitinase gene. Nat. Biotechnol. 14: 643-646.

Hayama, R., Yokoi, S., Tamaki, S., Yano, M. and Shimamoto, K. 2003. Adaptation of photoperiodic control pathways produces short-day flowering in rice. Nature 422: 719-722.

He, Z.H., Fujiki, M. and Kohorn, B.D. 1996. A cell wallassociated, receptor-like protein kinase. J. Biol. Chem. 271: 19789-19793.

He, Z.H., He, D.Z. and Kohorn, B.D. 1998. Requirement for the induced expression of a cell wall associated receptor kinase for survival during the pathogen response. Plant J. 14: 55-63.
Hourton-Cabassa, C., Ambard-Bretteville, F., Moreau, F., de Virville, J.D., Rémy, R. and Colas des Francs-Small, C. 1998. Stress induction of mitochondrial formate dehydrogenase in potato leaves. Plant Physiol. 116: 627-635.

Hunt, M.D. and Ryals, J.A. 1996. Systemic acquired resistance signal transduction. Crit. Rev. Plant Sci. 15: 583-606.

Huq, E., Tepperman, J.M. and Quail, P.H. 2000. GIGANTEA is a nuclear protein involved in phytochrome signaling in Arabidopsis. Proc. Natl. Acad. Sci. USA 97: 9789-9794.

Jach, G., Görnhardt, B., Mundy, J., Logemann, J., Pinsdorf, E., Leah, R., Schell, J. and Maas, C. 1995. Enhanced quantitative resistance against fungal disease by combinatorial expression of different barley antifungal proteins in transgenic tobacco. Plant J. 8: 97-109.

Jahn, R., Lang, T. and Sudhof, T.C. 2003. Membrane fusion. Cell 112: 519-533.

Jelitto-Van Dooren, E., Vidal, S. and Denecke, J. 1999. Anticipating endoplasmic reticulum stress: a novel early response before pathogenesis-related gene induction. Plant Cell 11: 1935-1943.

Kohorn, B.D. 2000. Plasma membrane-cell wall contacts. Plant Physiol. 124: 31-38.

Lally, D., Ingmire, P., Tong, H.-Y. and He, Z.-H. 2001. Antisense expression of a cell wall-associated protein kinase, WAK4, inhibits cell elongation and alters morphology. Plant Cell 13: 1317-1332.

Laurent, F., Labesse, G. and de Wit, P. 2000. Molecular cloning and partial characterization of a plant VAP33 homologue with a major sperm protein domain. Biochem. Biophys. Res. Commun. 270: 286-292.

Lee, , H.-ì, and Raskin, I. 1999. Purification, cloning, and expression of a pathogen inducible UDP-glucose:salicylic acid glucosyltransferase from tobacco. J. Biol. Chem. 274: 36637-36642.

Levy, S. and Stachelin, L.A. 1992. Synthesis, assembly and function of plant cell wall macromolecules. Curr. Opin. Cell Biol. 4: 856-862.

Liu, D., Raghothama, K.G., Hasegawa, P.M. and Bressan, R.A. 1994. Osmotin overexpression in potato delays development of disease symptoms. Proc. Natl. Acad. Sci. USA 91: $1888-1892$.

Maleck, K., Levine, A., Eulgem, T., Morgan, A., Schmid, J., Lawton, K.A., Dangl, J.L. and Dietrich, R.A. 2000. The transcriptome of Arabidopsis thaliana during systemic acquired resistance. Nat. Genet. 26: 403-410.

Maxwell, D.P., Wang, Y. and McIntosh, L. 1999. The alternative oxidase lowers mitochondrial reactive oxygen production in plant cells. Proc. Natl. Acad. Sci. 96: 8271-8276.

Nelson, D.E., Glaunsinger, B. and Bohnert, H.J. 1997. Abundant accumulation of the calcium-binding molecular chaperone calreticulin in specific floral tissues of Arabidopsis thaliana. Plant Physiol. 114: 29-37.

O'Donnell, P.J., Truesdale, M.R., Calvert, C.M., Dorans, A., Roberts, M.R. and Bowles, D.J. 1998. A novel tomato gene that rapidly responds to wound- and pathogen-related signals. Plant J. 14: 137-142.

Obendorf, R.L., Koch, J.L., Gorecki, R.J., Amable, R.A. and Aveni, M.T. 1990. Methanol accumulation in maturing seeds. J. Exp. Bot. 41: 489495.

Ordog, S.H., Higgins, V.J. and Vanlerberghe, G.C. 2002. Mitochondrial alternative oxidase is not a critical component of plant viral resistance but may play a role in the hypersensitive response. Plant Physiol. 129: 18581865 . 
Pábon, C., Modrusan, Z., Ruvolo, M.V., Coleman, I.M., Daniel, S., Yue, H., Arnold, L.J. and Reynolds, M.A. 2001. Optimized T7 amplification system for microarray analysis. Biotechniques 31: 874-879.

Park, A.R., Cho, S.K., Yun, U.J., Jin, M.Y., Lee, S.H., SachettoMartins, G. and Park, O.K. 2001. Interaction of the Arabidopsis receptor protein kinase Wakl with a glycine-rich protein, AtGRP-3. J. Biol. Chem. 276: 26688-26693.

Park, D.H., Somers, D.E., Kim, Y.S., Choy, Y.H., Lim, H.K., Soh, M.S., Kim, H.J., Kay, S.A. and Nam, H.G. 1999. Control of circadian rhythms and photoperiodic flowering by the Arabidopsis GIGANTEA gene. Science 285: $1579-1582$.

Poirier, G.M.C. and Erlander, M.G. 1998. Postdifferential display: parallel processing of candidates using small amounts of RNA. Methods 16: 444-452.

Quackenbush, J. 2002. Microarray data normalization and transformation. Nat. Genet. 32: 496-501.

Reymond, P., Weber, H., Damond, M. and Farmer, E.E. 2000. Differential gene expression in response to mechanical wounding and insect feeding in Arabidopsis. Plant Cell 12: $707-719$

Ryals, J.A., Neuenschwander, U.H., Willits, M.G., Molina, A., Steiner, H.Y. and Hunt, M.D. 1996. Systemic acquired resistance. Plant Cell 8: 1809-1819.

Salinas-Mondragón, R.E., Garcidueñas-Piña, C. and Guzmán, P. 1999. Early elicitor induction in members of a novel multigene family coding for highly related RING-H2 proteins in Arabidopsis thaliana. Plant Mol. Biol. 40: 579-590.

Sato, K. and Wickner, W. 1998. Functional reconstitution of Ypt7p GTPase and a purified vacuole SNARE complex. Science 281: 700-702.

Schachermayr, G., Siedler, H., Gale, M.D., Winzeler, H., Winzeler, M. and Keller, B. 1994. Identification and localization of molecular markers linked to the $\operatorname{Lr} 9$ leaf rust resistance gene of wheat. Theoret. Appl. Genet. 88: $110-115$.

Schena, M., Shalon, D., Davis, R.W. and Brown, P.O. 1995. Quantitative monitoring of gene-expression patterns with a complementary-DNA microarray. Science 270: 467-470.

Scheufler, C., Brinker, A., Bourenkov, G., Pegoraro, S., Moroder, L., Bartunik, H., Hartl, F.U. and Moarefi, I. 2000. Structure of TPR domain-peptide complexes: critical elements in the assembly of the Hsp70-Hsp90 multichaperone machine. Cell 101: 199-210.

Schweizer, P., Christoffel, A. and Dudler, R. 1999a. Transient expression of members of the germin-like gene family in epidermal cells of wheat confers disease resistance. Plant $\mathbf{J}$. 20: $540-552$

Schweizer, P., Pokorny, J., Abderhalden, O. and Dudler, R. 1999b. A transient assay system for the functional assessment of defense-related genes in wheat. Mol. PlantMicrobe Interact. 12: 647-654.
Schweizer, P., Pokorny, J., Schulze-Lefert, P. and Dudler, R. 2000. Double-stranded RNA interferes with gene function at the single-cell level in cereals. Plant J. 24: 895-903.

Schweizer, P., Kmecl, A., Carpita, N. and Dudler, R. 2000. A soluble carbohydrate elicitor from Blumeria graminis f. sp tritici is recognized by a broad range of cereals. Physiol. Mol. Plant Pathol. 56: 157-167.

Shalon, D., Smith, S.J. and Brown, P.O. 1996. A DNA microarray system for analyzing complex DNA samples using two-color fluorescent probe hybridization. Genome Res. 6: 639-645.

Skehel, P.A., Martin, K.C., Kandel, E.R. and Bartsch, D. 1995. A VAMP-binding protein from Aplysia required for neurotransmitter release. Science 269: 1580-1583.

Sticher, L., MauchMani, B. and Metraux, J.P. 1997. Systemic acquired resistance. Annu. Rev. Phytopathol. 35: 235-270.

Südhof, T.C. 1997. Function of Rab3 GDP-GTP exchange. Neuron 18: 519-522.

Tseng, T.S., Salome, P.A., McClung, C.R. and Olszewski, N.E. 2004. SPINDLY and GIGANTEA interact and act in Arabidopsis thaliana pathways involved in light responses, flowering, and rhythms in cotyledon movements. Plant Cell 16: $1550-1563$.

Vanlerberghe, G.C., Robson, C.A. and Yip, J.Y.H. 2002. Induction of mitochondrial alternative oxidase in response to a cell signal pathway down-regulating the cytochrome pathway prevents programmed cell death. Plant Physiol 129: $1829-1842$.

Vos, P., Hogers, R., Bleeker, M., Reijans, M., van de Lee, T., Hornes, M., Frijters, A., Pot, J., Peleman, J. and Kuiper, M. 1995. AFLP: a new technique for DNA fingerprinting. Nucl Acids Res. 23: 4407-4414.

Wäspi, U., Schweizer, P. and Dudler, R. 2001. Syringolin reprograms wheat to undergo hypersensitive cell death in a compatible interaction with powdery mildew. Plant Cell 13: 153-161.

Wäspi, U., Blanc, D., Winkler, T., Ruedi, P. and Dudler, R. 1998. Syringolin, a novel peptide elicitor from Pseudomonas syringae pv. syringae that induces resistance to Pyricularia oryzae in rice. Mol. Plant-Microbe Interact. 11: 727-733.

Wäspi, U., Misteli, B., Hasslacher, M., Jandrositz, A., Kohlwein, S.D., Schwab, H. and Dudler, R. 1998. The defenserelated rice gene $\operatorname{Pir} 7 b$ encodes an alpha/beta hydrolase fold protein exhibiting esterase activity towards naphthol AS-esters. Eur. J. Biochem. 254: 32-37.

Yahiaoui, N., Srichumpa, P., Dudler, R. and Keller, B. 2004. Genome analysis at different ploidy levels allows cloning of the powdery mildew resistance gene $P m 3 b$ from hexaploid wheat. Plant J. 37: 528-538.

Zhang, L., Meakin, H. and Dickinson, M. 2003. Isolation of genes expressed during compatible interactions between leaf rust (Puccinia triticina) and wheat using cDNA-AFLP. Mol Plant Pathol. 4: 469-477. 